\title{
Mid-arm muscle circumference as a substantial factor against mortality among people with elevated gamma gaps
}

\author{
Yuan-Ping Chao ${ }^{1}$, Yi-Fen Lai ${ }^{1}$, Tung-Wei Kao ${ }^{1,2}$, Tao-Chun Peng ${ }^{1}$, Yuan-Yung Lin ${ }^{3,4}$, Mu- \\ Tsun Shih ${ }^{4,5}$, Wei-Liang Chen ${ }^{1,2,3}$ and Li-Wei Wu ${ }^{1,2,4}$ \\ ${ }^{1}$ Division of Family Medicine, Department of Family and Community Medicine, Tri-Service General Hospital and School of \\ Medicine, National Defense Medical Center, Taipei, Taiwan, Republic of China \\ ${ }^{2}$ Division of Geriatric Medicine, Department of Family and Community Medicine, Tri-Service General Hospital and School of \\ Medicine, National Defense Medical Center, Taipei, Taiwan, Republic of China \\ ${ }^{3}$ Department of Otolaryngology-Head and Neck Surgery, Tri-Service General Hospital and School of Medicine, National \\ Defense Medical Center, Taipei, Taiwan, Republic of China \\ ${ }^{4}$ Graduate Institute of Medical Sciences, National Defense Medical Center, Taipei, Taiwan, Republic of China \\ ${ }^{5}$ Division of Urology, Department of Surgery, Tri-Service General Hospital and School of Medicine, National Defense Medical \\ Center, Taipei, Taiwan, Republic of China
}

Correspondence to: Li-Wei Wu, email: bigmouth0825@hotmail.com

Keywords: anthropometric parameters, MAMC, gamma gap, NHANES, mortality

Received: April 14, $2017 \quad$ Accepted: July 07, $2017 \quad$ Published: July 19, 2017

Copyright: Chao et al. This is an open-access article distributed under the terms of the Creative Commons Attribution License 3.0 (CC BY 3.0), which permits unrestricted use, distribution, and reproduction in any medium, provided the original author and source are credited.

\section{ABSTRACT}

Gamma gap is the difference in total serum proteins and albumin and an elevated gamma gap is related to infections, malignancy, and rheumatic diseases. An elevated gamma gap is also associated with higher mortality due to the correlation with inflammatory status. The study aimed to utilize mid-arm muscle circumference (MAMC) to assist in predicting all-cause mortality, cancer mortality, and cardiovascular mortality in people with elevated gamma gaps. Data were obtained from the third U.S. National Health and Nutrition Examination Survey (1988-1994), which contained 14,011 adults aged 20 to 90 years during up to 14.3 years of follow-up. The Primary analysis examined MAMC in tertiles and revealed the demographic and characteristics of the study population. Receiver operating characteristic curve analysis was used and the most suitable cut-off point of gamma gap was $3.65 \mathrm{~g} / \mathrm{dl}$. The secondary analysis employed Cox proportional hazards models stratified by age, gender and body mass index to evaluate the hazard ratios for all-cause mortality, cancer mortality, and cardiovascular mortality associated with the MAMC. As the MAMC tertiles increased in group with gamma gap $\geq 3.65 \mathrm{~g} / \mathrm{dl}$, individuals with elder age (60-90 years), normal range of body mass index $\left(19-24.9 \mathrm{~kg} / \mathrm{m}^{2}\right)$, and male gender tended to have lower hazard ratios for all-cause mortality, cancer mortality, and cardiovascular mortality. These substantial findings indicate that higher MAMC may be a protective factor of all cause-mortality, cancer mortality, and cardiovascular mortality among older male with normal body mass index and elevated gamma gaps.

\section{INTRODUCTION}

The definition of gamma gap is the difference in total serum proteins and albumin, and a value above 3.5 or $4.0 \mathrm{~g} / \mathrm{dl}$ is considered to be elevated. An elevated gamma gap was indicative of infections, malignancy, or other generalized inflammation. Previous literature has shown strong correlation between gamma gap and mortality, which may be due to gamma gap characterizing inflammatory status [1]. Among those with high levels of gamma gap, having adequate cardiorespiratory fitness is of importance in reducing mortality [2]. Of additional interest to the present study is a less investigated factor related to mortality among people with an elevated gamma gap, the 
mid-arm muscle circumference (MAMC). The MAMC is calculated as: mid-upper arm circumference (MAC) $(\mathrm{cm})$ $-0.3142 \mathrm{x}$ triceps skinfold (TS) thickness ( $\mathrm{mm})$, which is a single most portable and simple measurement. It is salient to establish the contributions of the widely applicable, convenient, and inexpensive anthropometric indices as well as potential mechanisms linking anthropometric indices to mortality to inform the development of specific prevention and intervention strategies in people with elevated gamma gaps. The aim of this investigation is to explore the potential protective effects of the MAMC on mortality in people with elevated gamma gaps. The National Health and Nutrition Examination Survey (NHANES) III database was adopted in this study. We assessed the associations of MAMC and all-cause mortality, cancer mortality, and cardiovascular (CV) mortality among people with and without elevated gamma gaps, respectively.

\section{RESULTS}

\section{Preliminary analysis}

The study included 14,011 adults with 6,688 (47.7\%) male and 7,323 (52.3\%) female participants. The mean MAMC was $25.9 \pm 3.9 \mathrm{~cm}$ and the mean age was $47.8 \pm 19.1$ years. In our analytical cohort study, 3,432 deaths occurred during a mean follow-up of 14.3 years, including 1,898 male and 1,534 female.

\section{Study sample characteristics}

Table 1 presented the demographic and clinical characteristics of the study population by MAMC tertiles. Of the participants, higher levels of body mass index (BMI), systolic blood pressure (SBP), diastolic blood pressure (DBP), serum total cholesterol (TC), serum total triglycerides (TG), serum glucose, serum low-density lipoprotein (LDL), serum uric acid (UA), aspartate aminotransferase (AST), alanine aminotransferase (ALT), serum total bilirubin, and serum albumin were observed in higher MAMC tertiles. However, higher gamma gap, serum high-density lipoprotein (HDL), and C-reactive protein (CRP) levels were shown in the lower MAMC tertiles. Male participants increased as female participants decreased in the higher MAMC tertiles. Asthma and smoking tended to increase in the higher MAMC tertiles while other cancer had an opposite trend. Higher percentages of non-Hispanic white, type 2 diabetes mellitus (DM), stroke, and congestive heart failure $(\mathrm{CHF})$ were presented in the higher MAMC tertiles. Nonetheless, the maximal percentage of skin cancer was in the second tertile of MAMC.

\section{The cut-off point of the gamma gap}

To further investigated the relationship between the MAMC and all-cause mortality, cancer mortality, and CV mortality, we divided the participants into 2 groups based on the gamma gap level. The $\mathrm{P}$ value of the interaction test between MAMC and gamma gap was $<0.001$. The receiver operating characteristic (ROC) curves of gamma gap for detecting all-cause mortality, cancer mortality, and CV mortality was performed. ROC curve was used for predicting the ethnic-specific cut-off points of gamma gap and the area under curve (AUC) was calculated with 95\% confidence interval (CI). The optimal AUC (95\% CI) was $0.534(0.523-0.545)$ for all-cause mortality, 0.533 $(0.512-0.555)$ for cancer mortality, and $0.528(0.512-$ 0.544 ) for CV mortality when gamma gap was $3.65 \mathrm{~g} / \mathrm{dl}$. The three mortality outcomes had identical cut-off value of gamma gap; therefore, we divided the participants into groups with gamma gap $<3.65 \mathrm{~g} / \mathrm{dl}$ and $\geq 3.65 \mathrm{~g} / \mathrm{dl}$.

\section{Association between the MAMC and all-cause mortality, cancer mortality, and cardiovascular mortality}

Cox proportional hazards models stratified by age, BMI, and gender were utilized to determine the hazard ratios (HRs) for all-cause mortality, cancer mortality, and $\mathrm{CV}$ mortality associated with the MAMC in the 2 gamma gap groups. Multivariable adjusted analyses were conducted and the results were shown in Tables 2-10.

Increasing MAMC tertiles were significantly associated with decreasing HRs for all-cause mortality among 60-90 years old individuals with gamma gap $\geq 3.65 \mathrm{~g} / \mathrm{dl}$ (Table 2) and those with BMI 19-24.9 kg/m² and gamma gap $\geq 3.65 \mathrm{~g} / \mathrm{dl}$ (Table 3 ). Moreover, in male participants, the MAMC was in significant association with decreasing HRs for all-cause mortality regardless of the gamma gap levels (Table 4).

No statistically significant correlation was noted between MAMC and cancer mortality in both gamma gap groups stratified by age (Table 5). Increasing MAMC tertiles were statistically significant associated with lower HRs for cancer mortality in male participants with gamma gap $\geq 3.65 \mathrm{~g} / \mathrm{dl}$ (Table 6) and in participants with BMI 19$24.9 \mathrm{~kg} / \mathrm{m}^{2}$ and gamma gap $\geq 3.65 \mathrm{~g} / \mathrm{dl}$ (Table 7).

Participants aged 60-90 years with gamma gap $\geq$ $3.65 \mathrm{~g} / \mathrm{dl}$ (Table 8), those with BMI 19-24.9 kg/m² and gamma gap $\geq 3.65 \mathrm{~g} / \mathrm{dl}$ (Table 9), and male participants in group with gamma gap $\geq 3.65 \mathrm{~g} / \mathrm{dl}$ (Table 10) had significantly positive association between higher MAMC tertiles and lower HRs for CV mortality. Furthermore, individuals aged 20-39 years with gamma gap $<3.65 \mathrm{~g} / \mathrm{dl}$ also had the identical association between MAMC and $\mathrm{CV}$ mortality.

According to Tables 2-10, in the group with gamma gap $<3.65 \mathrm{~g} / \mathrm{dl}$, the association between the MAMC tertiles and HRs for all-cause mortality, cancer mortality, and CV mortality were lack of statistical significance.

In conclusion, while the MAMC tertiles increased in the elevated gamma gap group (gamma gap $\geq 3.65 \mathrm{~g} / \mathrm{dl}$ ), 
Table 1: Characteristics of the study participants by mid-arm muscle circumference tertiles

\begin{tabular}{|c|c|c|c|c|c|}
\hline \multirow{3}{*}{ Characteristics of the study participants } & \multicolumn{3}{|c|}{ Tertiles of mid-arm muscle circumference $(\mathrm{cm})$} & \multirow{3}{*}{$\begin{array}{c}\text { Total } \\
n=14,011\end{array}$} & \multirow{3}{*}{$P$ for trend } \\
\hline & T1 (18.0-27.2 cm) & T2 $(27.3-29.5 \mathrm{~cm})$ & T3 $(29.6-40.0 \mathrm{~cm})$ & & \\
\hline & $n=4,670$ & $n=4,670$ & $n=4,671$ & & \\
\hline \multicolumn{6}{|l|}{ Continuous variables ${ }^{a}$} \\
\hline MAMC (cm), mean (SE) & $21.673(1.410)$ & $25.739(1.161)$ & $30.373(2.081)$ & $25.929(3.897)$ & $<0.001$ \\
\hline Gamma Gap (g/dL), mean (SE) & $3.259(0.477)$ & $3.258(0.481)$ & $3.223(0.482)$ & $3.247(0.480)$ & $<0.001$ \\
\hline Age (years), mean (SE) & $46.130(19.994)$ & $50.840(19.972)$ & $46.360(16.829)$ & $47.780(19.112)$ & $<0.001$ \\
\hline BMI $\left(\mathrm{kg} / \mathrm{m}^{2}\right)$, mean $(\mathrm{SE})$ & $24.010(4.012)$ & $27.130(4.889)$ & $29.290(5.254)$ & $26.810(5.218)$ & $<0.001$ \\
\hline SBP (mmHg), mean (SE) & $120.170(23.101)$ & $127.830(22.694)$ & $128.020(18.885)$ & $125.340(21.947)$ & $<0.001$ \\
\hline DBP (mmHg), mean (SE) & $68.110(13.085)$ & $72.280(12.836)$ & $76.780(12.030)$ & $72.390(13.144)$ & $<0.001$ \\
\hline Serum TG (mg/dL), mean (SE) & $122.090(96.320)$ & $144.880(106.942)$ & $166.730(137.438)$ & $144.580(116.335)$ & $<0.001$ \\
\hline Serum total cholesterol (mg/dL), mean (SE) & $203.190(45.959)$ & $207.310(45.771)$ & $207.320(42.813)$ & $205.940(44.909)$ & $<0.001$ \\
\hline Serum HDL-cholesterol (mg/dL), mean (SE) & $56.860(15.856)$ & $50.770(15.387)$ & $45.960(13.731)$ & $51.200(15.667)$ & $<0.001$ \\
\hline Serum LDL-cholesterol (mg/dL), mean (SE) & $122.130(38.758)$ & $129.190(38.832)$ & $132.060(37.862)$ & $127.810(38.707)$ & $<0.001$ \\
\hline Serum glucose (mg/dL), mean (SE) & $94.500(33.250)$ & $102.180(38.038)$ & $102.820(38.649)$ & $100.17(36.947)$ & $<0.001$ \\
\hline Serum CRP (mg/dL), mean (SE) & $0.452(0.836)$ & $0.500(0.781)$ & $0.437(0.663)$ & $0.463(0.764)$ & $<0.001$ \\
\hline Serum UA (mg/dL), mean (SE) & $4.509(1.258)$ & $5.422(1.389)$ & $6.122(1.372)$ & $5.451(1.495)$ & $<0.001$ \\
\hline AST (U/L), mean (SE) & $20.080(12.203)$ & $22.520(18.028)$ & $24.730(16.610)$ & $22.440(15.922)$ & $<0.001$ \\
\hline ALT (U/L), mean (SE) & $14.280(13.059)$ & $17.320(15.723)$ & $22.490(20.143)$ & $18.030(16.910)$ & $<0.001$ \\
\hline Serum total bilirubin (umol/L), mean (SE) & $0.529(0.301)$ & $0.590(0.319)$ & $0.667(0.365)$ & $0.595(0.334)$ & $<0.001$ \\
\hline Serum albumin (g/dL), mean (SE) & $4.081(0.372)$ & $4.135(0.383)$ & $4.216(0.358)$ & $4.144(0.375)$ & $<0.001$ \\
\hline \multicolumn{6}{|l|}{ Categorical variables $^{b}$} \\
\hline Gender (male), $N(\%)$ & $272(5.8)$ & $2314(49.6)$ & $4102(87.8)$ & $6688(47.7)$ & $<0.001$ \\
\hline Non-Hispanic white, $N(\%)$ & $1195(25.6)$ & $1320(28.3)$ & $1300(27.8)$ & $3815(27.2)$ & $<0.001$ \\
\hline Type 2 diabetes mellitus, $N(\%)$ & $250(5.4)$ & $429(9.2)$ & $409(8.8)$ & $1088(7.8)$ & $<0.001$ \\
\hline Malignancy, $N(\%)$ & $203(4.3)$ & $201(4.3)$ & $117(2.5)$ & $521(3.7)$ & $<0.001$ \\
\hline Stroke, $N(\%)$ & $97(2.1)$ & $156(3.3)$ & $100(2.1)$ & $353(2.5)$ & $<0.001$ \\
\hline Congestive heart failure, $N(\%)$ & $107(2.3)$ & $207(4.4)$ & $167(3.6)$ & $481(3.4)$ & $<0.001$ \\
\hline Asthma, $N(\%)$ & $300(6.4)$ & $323(6.9)$ & $345(7.4)$ & $968(6.9)$ & 0.251 \\
\hline Smoking, $N(\%)$ & $76(1.6)$ & $520(11.1)$ & $983(21.0)$ & 1579 (11.3) & $<0.001$ \\
\hline
\end{tabular}

Abbreviations:

$\mathrm{N}$, number; SE, standard errors; MAMC, mid-arm muscle circumference; BMI, body mass index; SBP, systolic blood pressure; DBP, diastolic blood pressure; Serum TG, serum total triglycerides; HDL, high-density lipoprotein; LDL, low-density lipoprotein; Serum CRP, serum C-reactive protein; Serum UA, serum uric acid; AST, aspartate aminotransferase; ALT, alanine aminotransferase.

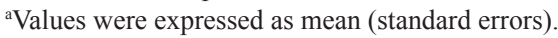

${ }^{b}$ Values in the categorical variables were expressed as number (\%).

individuals with elder age (60-90 years), normal range of BMI $\left(19-24.9 \mathrm{~kg} / \mathrm{m}^{2}\right)$, and male gender tended to have lower HRs for all-cause mortality, cancer mortality, and $\mathrm{CV}$ mortality. The results indicated higher MAMC may be a protective factor of all-cause mortality, cancer mortality, and $\mathrm{CV}$ mortality.

\section{DISCUSSION}

We discovered a statistical significant lowering down of HRs of mortality in higher MAMC tertiles among older male participants with normal BMI values and within the group with gamma gap $\geq 3.65 \mathrm{~g} / \mathrm{dl}$. This 

Table 2: Cox proportional hazards regression of all-cause mortality for mid-arm muscle
circumference stratified by age in the US individuals

\begin{tabular}{|c|c|c|c|c|c|c|c|}
\hline \multicolumn{4}{|c|}{ GammaGap $<3.65(\mathrm{~g} / \mathrm{dL})$} & \multicolumn{4}{|c|}{ GammaGap $\geq 3.65(\mathrm{~g} / \mathrm{dL})$} \\
\hline Models a & Tertiles of MAMC & $\begin{array}{l}\text { Hazard Ratio } \\
(95 \% \text { CI) }\end{array}$ & $P$-value & Models a & Tertiles of MAMC & $\begin{array}{l}\text { Hazard Ratio } \\
(95 \% \text { CI })\end{array}$ & $P$-value \\
\hline \multicolumn{4}{|c|}{ Aged 20-39 years } & \multicolumn{4}{|c|}{ Aged 20-39 years } \\
\hline Model 1 & $\begin{array}{l}\text { T2 v.s. T1 } \\
\text { T3 v.s. T1 }\end{array}$ & $\begin{array}{l}1.77(1.12-2.81) \\
2.66(1.75-4.04)\end{array}$ & $\begin{array}{c}0.015 \\
<0.001\end{array}$ & Model 1 & $\begin{array}{l}\text { T2 v.s. T1 } \\
\text { T3 v.s. T1 }\end{array}$ & $\begin{array}{l}1.69(0.88-3.23) \\
1.81(0.94-3.48)\end{array}$ & $\begin{array}{l}0.112 \\
0.076\end{array}$ \\
\hline Model 2 & $\begin{array}{l}\text { T2 v.s. T1 } \\
\text { T3 v.s. T1 }\end{array}$ & $\begin{array}{l}1.32(0.75-2.33) \\
1.58(0.83-3.00)\end{array}$ & $\begin{array}{l}0.330 \\
0.159\end{array}$ & Model 2 & $\begin{array}{l}\text { T2 v.s. T1 } \\
\text { T3 v.s. T1 }\end{array}$ & $\begin{array}{l}1.31(0.65-2.65) \\
0.94(0.38-2.33)\end{array}$ & $\begin{array}{l}0.457 \\
0.891\end{array}$ \\
\hline Model 3 & $\begin{array}{l}\text { T2 v.s. T1 } \\
\text { T3 v.s. T1 }\end{array}$ & $\begin{array}{l}1.34(0.76-2.37) \\
1.66(0.87-3.19)\end{array}$ & $\begin{array}{l}0.309 \\
0.126\end{array}$ & Model 3 & $\begin{array}{l}\text { T2 v.s. T1 } \\
\text { T3 v.s. T1 }\end{array}$ & $\begin{array}{l}1.48(0.71-3.09) \\
0.98(0.39-2.47)\end{array}$ & $\begin{array}{l}0.299 \\
0.960\end{array}$ \\
\hline Model 4 & $\begin{array}{l}\text { T2 v.s. T1 } \\
\text { T3 v.s. T1 }\end{array}$ & $\begin{array}{l}1.34(0.76-2.37) \\
1.65(0.86-3.17)\end{array}$ & $\begin{array}{l}0.312 \\
0.132\end{array}$ & Model 4 & $\begin{array}{l}\text { T2 v.s. T1 } \\
\text { T3 v.s. T1 }\end{array}$ & $\begin{array}{l}1.43(0.68-3.01) \\
0.97(0.38-2.48)\end{array}$ & $\begin{array}{l}0.341 \\
0.950\end{array}$ \\
\hline \multicolumn{4}{|c|}{ Aged $40-59$ years } & \multicolumn{4}{|c|}{ Aged $40-59$ years } \\
\hline Model 1 & $\begin{array}{l}\text { T2 v.s. T1 } \\
\text { T3 v.s. T1 }\end{array}$ & $\begin{array}{l}1.64(1.24-2.16) \\
1.36(1.04-1.78)\end{array}$ & $\begin{array}{c}<0.001 \\
0.026\end{array}$ & Model 1 & $\begin{array}{l}\text { T2 v.s. T1 } \\
\text { T3 v.s. T1 }\end{array}$ & $\begin{array}{l}1.59(1.02-2.49) \\
1.44(0.91-2.26)\end{array}$ & $\begin{array}{l}0.040 \\
0.117\end{array}$ \\
\hline Model 2 & $\begin{array}{l}\text { T2 v.s. T1 } \\
\text { T3 v.s. T1 }\end{array}$ & $\begin{array}{l}1.20(0.88-1.65) \\
0.88(0.60-1.27)\end{array}$ & $\begin{array}{l}0.253 \\
0.481\end{array}$ & Model 2 & $\begin{array}{l}\text { T2 v.s. T1 } \\
\text { T3 v.s. T1 }\end{array}$ & $\begin{array}{l}1.15(0.71-1.85) \\
0.69(0.40-1.20)\end{array}$ & $\begin{array}{l}0.567 \\
0.186\end{array}$ \\
\hline Model 3 & $\begin{array}{l}\text { T2 v.s. T1 } \\
\text { T3 v.s. T1 }\end{array}$ & $\begin{array}{l}1.21(0.88-1.66) \\
0.88(0.61-1.28)\end{array}$ & $\begin{array}{l}0.233 \\
0.513\end{array}$ & Model 3 & $\begin{array}{l}\text { T2 v.s. T1 } \\
\text { T3 v.s. T1 }\end{array}$ & $\begin{array}{l}1.18(0.72-1.92) \\
0.77(0.43-1.36)\end{array}$ & $\begin{array}{l}0.510 \\
0.370\end{array}$ \\
\hline Model 4 & $\begin{array}{l}\text { T2 v.s. T1 } \\
\text { T3 v.s. T1 }\end{array}$ & $\begin{array}{l}1.21(0.88-1.66) \\
0.88(0.60-1.28)\end{array}$ & $\begin{array}{l}0.240 \\
0.492\end{array}$ & Model 4 & $\begin{array}{l}\text { T2 v.s. T1 } \\
\text { T3 v.s. T1 }\end{array}$ & $\begin{array}{l}1.14(0.70-1.87) \\
0.77(0.43-1.38)\end{array}$ & $\begin{array}{l}0.596 \\
0.382\end{array}$ \\
\hline \multicolumn{4}{|c|}{ Aged 60-90 years } & \multicolumn{4}{|c|}{ Aged 60-90 years } \\
\hline Model 1 & $\begin{array}{l}\text { T2 v.s. T1 } \\
\text { T3 v.s. T1 }\end{array}$ & $\begin{array}{l}1.17(1.06-1.30) \\
0.88(0.78-0.99)\end{array}$ & $\begin{array}{l}0.002 \\
0.034\end{array}$ & Model 1 & $\begin{array}{l}\text { T2 v.s. T1 } \\
\text { T3 v.s. T1 }\end{array}$ & $\begin{array}{l}0.89(0.73-1.07) \\
0.89(0.72-1.09)\end{array}$ & $\begin{array}{l}0.220 \\
0.268\end{array}$ \\
\hline Model 2 & $\begin{array}{l}\text { T2 v.s. T1 } \\
\text { T3 v.s. T1 }\end{array}$ & $\begin{array}{l}1.02(0.91-1.15) \\
0.91(0.79-1.06)\end{array}$ & $\begin{array}{l}0.744 \\
0.223\end{array}$ & Model 2 & $\begin{array}{l}\text { T2 v.s. T1 } \\
\text { T3 v.s. T1 }\end{array}$ & $\begin{array}{l}0.74(0.60-0.90) \\
0.71(0.56-0.91)\end{array}$ & $\begin{array}{l}0.004 \\
0.008\end{array}$ \\
\hline Model 3 & $\begin{array}{l}\text { T2 v.s. T1 } \\
\text { T3 v.s. T1 }\end{array}$ & $\begin{array}{l}1.01(0.9-1.14) \\
0.9(0.78-1.05)\end{array}$ & $\begin{array}{l}0.839 \\
0.186\end{array}$ & Model 3 & $\begin{array}{l}\text { T2 v.s. T1 } \\
\text { T3 v.s. T1 }\end{array}$ & $\begin{array}{l}0.74(0.60-0.91) \\
0.67(0.52-0.86)\end{array}$ & $\begin{array}{l}0.005 \\
0.002\end{array}$ \\
\hline Model 4 & $\begin{array}{l}\text { T2 v.s. T1 } \\
\text { T3 v.s. T1 }\end{array}$ & $\begin{array}{c}1.01(0.9-1.14) \\
0.90(0.78-1.05)\end{array}$ & $\begin{array}{l}0.864 \\
0.170\end{array}$ & Model 4 & $\begin{array}{l}\text { T2 v.s. T1 } \\
\text { T3 v.s. T1 }\end{array}$ & $\begin{array}{l}0.75(0.61-0.93) \\
0.69(0.54-0.89)\end{array}$ & $\begin{array}{l}0.007 \\
0.004\end{array}$ \\
\hline
\end{tabular}

${ }^{a}$ Adjusted covariates:

Model $1=$ Unadjusted .

Model $2=$ Model $1+$ gender, race and body mass index (BMI).

Model 3 = Model $2+$ serum high-density lipoprotein (HDL), serum fasting glucose, serum total cholesterol, serum total bilirubin, serum aspartate aminotransferase (AST).

Model 4 = Model $3+$ history of congestive heart failure (CHF), stroke, malignancy and smoking.

results showed that higher MAMC may possess protective power over all-cause mortality, cancer mortality, and CV mortality in normal weight older male people with gamma gap $\geq 3.65 \mathrm{~g} / \mathrm{dl}$.

Previous literature suggested that MAMC could assist biochemical analysis to characterize undernutrition status [3]. MAMC could represent muscle mass due to its strong correlation with the accurate dual-energy X-ray absorptiometry (DEXA) [4]. Higher MAMC was an indicator of larger lean body mass in maintenance hemodialysis (MHD) patients and was also a potential predictor of better quality of life and survival rate [4].
Combined use of both waist circumference (WC) and MAMC provided simple measures of body composition to assess mortality risk in older men [5]. Moreover, Landi et al. reasoned that decreased MAMC was associated with mortality in elderly men and women [6].

Gamma gap is also known as paraprotein gap or globulin gap [7]. High gamma gap has important implications of inflammatory states [8, 9, 10]. Albumin, the most abundant protein in plasma, serves as a circulating depot for endogenous and exogenous compounds [11]; however, viral infection, malignancies and autoimmune diseases lead to excessive production 
Table 3: Cox proportional hazards regression of all-cause mortality for mid-arm muscle
circumference stratified by body mass index (BMI) in the US individuals GammaGap $<3.65(\mathrm{~g} / \mathrm{dL})$

\begin{tabular}{|c|c|c|c|c|c|c|c|}
\hline Models a & Tertiles of MAMC & $\begin{array}{c}\text { Hazard Ratio } \\
(95 \% \text { CI) }\end{array}$ & $P$-value & Models a & Tertiles of MAMC & $\begin{array}{c}\text { Hazard Ratio } \\
(95 \% \text { CI) }\end{array}$ & $P$-value \\
\hline \multicolumn{4}{|c|}{ BMI 19-24.9 $\left(\mathrm{kg} / \mathrm{m}^{2}\right)$} & \multicolumn{4}{|c|}{ BMI 19-24.9 $\left(\mathrm{kg} / \mathrm{m}^{2}\right)$} \\
\hline Model 1 & $\begin{array}{l}\text { T2 v.s. T1 } \\
\text { T3 v.s. T1 }\end{array}$ & $\begin{array}{l}1.51(1.33-1.73) \\
0.64(0.52-0.79)\end{array}$ & $\begin{array}{l}<0.001 \\
<0.001\end{array}$ & Model 1 & $\begin{array}{l}\text { T2 v.s. T1 } \\
\text { T3 v.s. T1 }\end{array}$ & $\begin{array}{l}1.58(1.23-2.01) \\
0.71(0.48-1.06)\end{array}$ & $\begin{array}{c}<0.001 \\
0.094\end{array}$ \\
\hline Model 2 & $\begin{array}{l}\text { T2 v.s. T1 } \\
\text { T3 v.s. T1 }\end{array}$ & $\begin{array}{l}0.87(0.73-1.04) \\
0.80(0.61-1.05)\end{array}$ & $\begin{array}{l}0.134 \\
0.108\end{array}$ & Model 2 & $\begin{array}{l}\text { T2 v.s. T1 } \\
\text { T3 v.s. T1 }\end{array}$ & $\begin{array}{l}0.70(0.51-0.96) \\
0.52(0.32-0.84)\end{array}$ & $\begin{array}{l}0.026 \\
0.007\end{array}$ \\
\hline Model 3 & $\begin{array}{l}\text { T2 v.s. T1 } \\
\text { T3 v.s. T1 }\end{array}$ & $\begin{array}{l}0.89(0.74-1.07) \\
0.83(0.63-1.08)\end{array}$ & $\begin{array}{l}0.202 \\
0.173\end{array}$ & Model 3 & $\begin{array}{l}\text { T2 v.s. T1 } \\
\text { T3 v.s. T1 }\end{array}$ & $\begin{array}{l}0.67(0.49-0.92) \\
0.51(0.31-0.81)\end{array}$ & $\begin{array}{l}0.014 \\
0.005\end{array}$ \\
\hline Model 4 & $\begin{array}{l}\text { T2 v.s. T1 } \\
\text { T3 v.s. T1 }\end{array}$ & $\begin{array}{l}0.90(0.75-1.08) \\
0.84(0.64-1.09)\end{array}$ & $\begin{array}{l}0.250 \\
0.189\end{array}$ & Model 4 & $\begin{array}{l}\text { T2 v.s. T1 } \\
\text { T3 v.s. T1 }\end{array}$ & $\begin{array}{l}0.66(0.47-0.91) \\
0.52(0.32-0.84)\end{array}$ & $\begin{array}{l}0.012 \\
0.008\end{array}$ \\
\hline \multicolumn{4}{|c|}{ BMI 25-29.9 $\left(\mathrm{kg} / \mathrm{m}^{2}\right)$} & \multicolumn{4}{|c|}{ BMI 25-29.9 $\left(\mathrm{kg} / \mathrm{m}^{2}\right)$} \\
\hline Model 1 & $\begin{array}{l}\text { T2 v.s. T1 } \\
\text { T3 v.s. T1 }\end{array}$ & $\begin{array}{l}1.97(1.67-2.33) \\
0.95(0.80-1.13)\end{array}$ & $\begin{array}{c}<0.001 \\
0.564\end{array}$ & Model 1 & $\begin{array}{l}\text { T2 v.s. T1 } \\
\text { T3 v.s. T1 }\end{array}$ & $\begin{array}{l}2.08(1.52-2.83) \\
1.82(1.31-2.52)\end{array}$ & $\begin{array}{l}<0.001 \\
<0.001\end{array}$ \\
\hline Model 2 & $\begin{array}{l}\text { T2 v.s. T1 } \\
\text { T3 v.s. T1 }\end{array}$ & $\begin{array}{l}1.09(0.90-1.31) \\
0.83(0.66-1.06)\end{array}$ & $\begin{array}{l}0.382 \\
0.138\end{array}$ & Model 2 & $\begin{array}{l}\text { T2 v.s. T1 } \\
\text { T3 v.s. T1 }\end{array}$ & $\begin{array}{l}1.06(0.75-1.50) \\
0.98(0.64-1.52)\end{array}$ & $\begin{array}{l}0.725 \\
0.943\end{array}$ \\
\hline Model 3 & $\begin{array}{l}\text { T2 v.s. T1 } \\
\text { T3 v.s. T1 }\end{array}$ & $\begin{array}{l}1.08(0.90-1.31) \\
0.83(0.65-1.05)\end{array}$ & $\begin{array}{l}0.401 \\
0.127\end{array}$ & Model 3 & $\begin{array}{l}\text { T2 v.s. T1 } \\
\text { T3 v.s. T1 }\end{array}$ & $\begin{array}{l}1.04(0.74-1.48) \\
0.89(0.57-1.37)\end{array}$ & $\begin{array}{l}0.811 \\
0.595\end{array}$ \\
\hline Model 4 & $\begin{array}{l}\text { T2 v.s. T1 } \\
\text { T3 v.s. T1 }\end{array}$ & $\begin{array}{l}1.07(0.89-1.30) \\
0.82(0.64-1.04)\end{array}$ & $\begin{array}{l}0.464 \\
0.105\end{array}$ & Model 4 & $\begin{array}{l}\text { T2 v.s. T1 } \\
\text { T3 v.s. T1 }\end{array}$ & $\begin{array}{l}1.06(0.74-1.50) \\
0.86(0.55-1.33)\end{array}$ & $\begin{array}{l}0.753 \\
0.495\end{array}$ \\
\hline \multicolumn{4}{|c|}{$\mathrm{BMI} \geq 30\left(\mathrm{~kg} / \mathrm{m}^{2}\right)$} & \multicolumn{4}{|c|}{$\mathrm{BMI} \geq 30\left(\mathrm{~kg} / \mathrm{m}^{2}\right)$} \\
\hline Model 1 & $\begin{array}{l}\text { T2 v.s. T1 } \\
\text { T3 v.s. T1 }\end{array}$ & $\begin{array}{l}1.39(1.00-1.93) \\
1.63(1.19-2.24)\end{array}$ & $\begin{array}{l}0.049 \\
0.002\end{array}$ & Model 1 & $\begin{array}{l}\text { T2 v.s. T1 } \\
\text { T3 v.s. T1 }\end{array}$ & $\begin{array}{l}1.57(0.94-2.61) \\
2.19(1.34-3.59)\end{array}$ & $\begin{array}{l}0.082 \\
0.002\end{array}$ \\
\hline Model 2 & $\begin{array}{l}\text { T2 v.s. T1 } \\
\text { T3 v.s. T1 }\end{array}$ & $\begin{array}{l}1.23(0.89-1.72) \\
1.34(0.94-1.91)\end{array}$ & $\begin{array}{l}0.214 \\
0.110\end{array}$ & Model 2 & $\begin{array}{l}\text { T2 v.s. T1 } \\
\text { T3 v.s. T1 }\end{array}$ & $\begin{array}{l}0.99(0.60-1.66) \\
1.17(0.69-2.00)\end{array}$ & $\begin{array}{l}0.983 \\
0.558\end{array}$ \\
\hline Model 3 & $\begin{array}{l}\text { T2 v.s. T1 } \\
\text { T3 v.s. T1 }\end{array}$ & $\begin{array}{l}1.24(0.89-1.73) \\
1.34(0.94-1.92)\end{array}$ & $\begin{array}{l}0.197 \\
0.104\end{array}$ & Model 3 & $\begin{array}{l}\text { T2 v.s. T1 } \\
\text { T3 v.s. T1 }\end{array}$ & $\begin{array}{l}0.97(0.58-1.63) \\
1.11(0.65-1.90)\end{array}$ & $\begin{array}{l}0.921 \\
0.693\end{array}$ \\
\hline Model 4 & $\begin{array}{l}\text { T2 v.s. T1 } \\
\text { T3 v.s. T1 }\end{array}$ & $\begin{array}{l}1.25(0.90-1.74) \\
1.37(0.96-1.96)\end{array}$ & $\begin{array}{l}0.185 \\
0.084\end{array}$ & Model 4 & $\begin{array}{l}\text { T2 v.s. T1 } \\
\text { T3 v.s. T1 }\end{array}$ & $\begin{array}{l}0.99(0.59-1.66) \\
1.20(0.70-2.05)\end{array}$ & $\begin{array}{l}0.973 \\
0.503\end{array}$ \\
\hline
\end{tabular}

${ }^{\mathrm{a} A d j u s t e d ~ c o v a r i a t e s:}$

Model 1 = Unadjusted.

Model 2 = Model $1+$ age, gender, and race.

Model 3 = Model $2+$ serum high-density lipoprotein (HDL), serum fasting glucose, serum total cholesterol, serum total bilirubin, serum aspartate aminotransferase (AST).

Model 4 = Model 3 + history of congestive heart failure (CHF), stroke, malignancy and smoking.

of immunoglobulins, which raise the level of gamma gap independent of albumin [12]. Despite only few surveys applies gamma gap to predict clinical outcomes, the operational definition of an elevated gamma gap is above $4.0 \mathrm{~g} / \mathrm{dl}$ [1]. Among hospitalized patients, hypoalbuminemia is a common sign in reflection of inflammation [13]. In addition, other cytokines in inflammatory process stimulate acute-phase proteins production and result in elevation of gamma gaps. Hyperglobulinemia accompanied by hypoalbuminemia is a frequent condition in chronic autoimmune disease [14]. Patients suffering from multiple myeloma or other immunoproliferative disease has been known to show gross divergences of serum proteins constitution in comparison with normal people, including hyperproteinemia and associated change in albuminglobulin ratio (AGR) [15]. A large retrospective cohort study conducted in Korea indicates that subjects with low AGR are at risk for increased all-cause mortality, cancer mortality, and cancer incidence [16]. Juraschek et al. asserts gamma gap is in strong association with all-cause mortality and specifically, death from pulmonary diseases [1]. After taking physical activity into consideration, Loprinzi et al. illustrate that moderate-to-vigorous physical activity (MVPA) reduces death from any cause among people with elevated gamma gaps [17]. 


\section{Table 4: Cox proportional hazards regression of all-cause mortality for mid-arm muscle circumference stratified by gender in the US individuals}

\begin{tabular}{|c|c|c|c|c|c|c|c|}
\hline \multicolumn{4}{|c|}{ GammaGap < $3.65(\mathrm{~g} / \mathrm{dL})$} & \multicolumn{4}{|c|}{ GammaGap $\geq 3.65(\mathrm{~g} / \mathrm{dL})$} \\
\hline Models a & Tertiles of MAMC & $\begin{array}{c}\text { Hazard Ratio } \\
(95 \% \text { CI })\end{array}$ & $P$-value & Models a & Tertiles of MAMC & $\begin{array}{c}\text { Hazard Ratio } \\
(95 \% \text { CI })\end{array}$ & $P$-value \\
\hline \multicolumn{4}{|c|}{ Male } & \multicolumn{4}{|c|}{ Male } \\
\hline Model 1 & $\begin{array}{l}\text { T2 v.s. T1 } \\
\text { T3 v.s. T1 }\end{array}$ & $\begin{array}{l}0.49(0.40-0.60) \\
0.24(0.20-0.30)\end{array}$ & $\begin{array}{l}<0.001 \\
<0.001\end{array}$ & Model 1 & $\begin{array}{l}\text { T2 v.s. T1 } \\
\text { T3 v.s. T1 }\end{array}$ & $\begin{array}{l}0.47(0.34-0.64) \\
0.22(0.16-0.30)\end{array}$ & $\begin{array}{l}<0.001 \\
<0.001\end{array}$ \\
\hline Model 2 & $\begin{array}{l}\text { T2 v.s. T1 } \\
\text { T3 v.s. T1 }\end{array}$ & $\begin{array}{l}0.76(0.62-0.94) \\
0.59(0.48-0.73)\end{array}$ & $\begin{array}{c}0.010 \\
<0.001\end{array}$ & Model 2 & $\begin{array}{l}\text { T2 v.s. T1 } \\
\text { T3 v.s. T1 }\end{array}$ & $\begin{array}{l}0.67(0.49-0.92) \\
0.49(0.35-0.68)\end{array}$ & $\begin{array}{c}0.012 \\
<0.001\end{array}$ \\
\hline Model 3 & $\begin{array}{l}\text { T2 v.s. T1 } \\
\text { T3 v.s. T1 }\end{array}$ & $\begin{array}{l}0.78(0.63-0.95) \\
0.61(0.49-0.75)\end{array}$ & $\begin{array}{c}0.014 \\
<0.001\end{array}$ & Model 3 & $\begin{array}{l}\text { T2 v.s. T1 } \\
\text { T3 v.s. T1 }\end{array}$ & $\begin{array}{l}0.65(0.47-0.89) \\
0.46(0.33-0.64)\end{array}$ & $\begin{array}{c}0.007 \\
<0.001\end{array}$ \\
\hline Model 4 & $\begin{array}{l}\text { T2 v.s. T1 } \\
\text { T3 v.s. T1 }\end{array}$ & $\begin{array}{l}0.78(0.63-0.95) \\
0.61(0.49-0.75)\end{array}$ & $\begin{array}{c}0.015 \\
<0.001\end{array}$ & Model 4 & $\begin{array}{l}\text { T2 v.s. T1 } \\
\text { T3 v.s. T1 }\end{array}$ & $\begin{array}{l}0.60(0.44-0.83) \\
0.44(0.31-0.61)\end{array}$ & $\begin{array}{c}0.002 \\
<0.001\end{array}$ \\
\hline \multicolumn{4}{|c|}{ Female } & \multicolumn{4}{|c|}{ Female } \\
\hline Model 1 & $\begin{array}{l}\text { T2 v.s. T1 } \\
\text { T3 v.s. T1 }\end{array}$ & $\begin{array}{l}1.39(1.22-1.57) \\
1.62(1.31-2.00)\end{array}$ & $\begin{array}{l}<0.001 \\
<0.001\end{array}$ & Model 1 & $\begin{array}{l}\text { T2 v.s. T1 } \\
\text { T3 v.s. T1 }\end{array}$ & $\begin{array}{l}1.06(0.85-1.33) \\
1.58(1.18-2.11)\end{array}$ & $\begin{array}{l}0.602 \\
0.002\end{array}$ \\
\hline Model 2 & $\begin{array}{l}\text { T2 v.s. T1 } \\
\text { T3 v.s. T1 }\end{array}$ & $\begin{array}{l}1.06(0.94-1.21) \\
1.46(1.18-1.81)\end{array}$ & $\begin{array}{l}0.334 \\
0.001\end{array}$ & Model 2 & $\begin{array}{l}\text { T2 v.s. T1 } \\
\text { T3 v.s. T1 }\end{array}$ & $\begin{array}{l}0.83(0.66-1.03) \\
1.23(0.92-1.65)\end{array}$ & $\begin{array}{l}0.096 \\
0.156\end{array}$ \\
\hline Model 3 & $\begin{array}{l}\text { T2 v.s. T1 } \\
\text { T3 v.s. T1 }\end{array}$ & $\begin{array}{l}1.05(0.93-1.19) \\
1.43(1.15-1.77)\end{array}$ & $\begin{array}{l}0.435 \\
0.001\end{array}$ & Model 3 & $\begin{array}{l}\text { T2 v.s. T1 } \\
\text { T3 v.s. T1 }\end{array}$ & $\begin{array}{l}0.80(0.64-1.01) \\
1.21(0.90-1.62)\end{array}$ & $\begin{array}{l}0.062 \\
0.208\end{array}$ \\
\hline Model 4 & $\begin{array}{l}\text { T2 v.s. T1 } \\
\text { T3 v.s. T1 }\end{array}$ & $\begin{array}{l}1.05(0.92-1.19) \\
1.41(1.14-1.75)\end{array}$ & $\begin{array}{l}0.049 \\
0.002\end{array}$ & Model 4 & $\begin{array}{l}\text { T2 v.s. T1 } \\
\text { T3 v.s. T1 }\end{array}$ & $\begin{array}{l}0.82(0.65-1.03) \\
1.26(0.93-1.69)\end{array}$ & $\begin{array}{l}0.091 \\
0.131\end{array}$ \\
\hline
\end{tabular}

adjusted covariates:

Model 1 = Unadjusted.

Model $2=$ Model $1+$ age, race and body mass index (BMI).

Model 3 = Model $2+$ serum high-density lipoprotein (HDL), serum fasting glucose, serum total cholesterol, serum total bilirubin, serum aspartate aminotransferase (AST).

Model 4 = Model $3+$ history of congestive heart failure (CHF), stroke, malignancy and smoking

Due to the correlation between high gamma gaps and inflammation, Juraschek et al. speculate that elevated gamma gaps have strong association with mortality [1].

Physical activity has salient influences in lowering down all-cause mortality [18]. Routine exercise modulates body composition through controlling weight and attenuating abdominal adiposity $[19,20]$. It can enhance lipid profiles [21, 22], insulin sensitivity [23, 24], cardiac function [25, 26] and improve autonomic tone [27] and inflammatory states [28]. During an inflammation process, activated cells produce cytokines, including interleukin-6 (IL-6), interleukin-1 $\beta(\mathrm{IL}-1 \beta)$, tumor necrosis factor a (TNF- $\alpha$ ), interferon- $\gamma($ IFN- $\gamma)$, and transforming growth factor- $\beta$ (TGF- $\beta$ ). These pro-inflammatory cytokines impede normal physical function by production of oxygen free radicals, apoptosis, and activation of leukocytes [29, 30, 31]. Appropriate exercise affects beneficially the inflammatory cytokines, and cause reduction of IL-6 [32], TNF- $\alpha$ [33], and IFN- $\gamma$ [34]. Considering the above mentioned, we assume appropriate exercise possesses moderation effects on inflammation and plays a major role in lowering down mortality risk among population with high gamma gap. This conclusion is in consistent with Loprinzi et al., who suggests physical activity is beneficial in mortality among patients with high levels of gamma gap [17].

However, evaluating exercise requires standardized questionnaires, even trained personnel, and current investigations utilize different methods to acquire data. These high heterogeneity surveys can engender bias in future performing meta-regression analyses. Therefore, we use measurable anthropometric data in this study to reflect physical activity. As physical activity is associated with muscle mass [35], and MAMC can well represent muscle mass [4], we employed the MAMC to predict mortality of people with normal and elevated gamma gap in this survey. Noteworthy, in the group with gamma gap $\geq 3.65 \mathrm{~g} / \mathrm{dl}$, the HRs of all-cause mortality, cancer mortality, and CV mortality decreased as MAMC increased among older male participants. Genetic factors, hormones effects, muscle capacity and physical function may explain for the presence of gender differences of the 


\section{Table 5: Cox proportional hazards regression of cancer mortality for mid-arm muscle circumference stratified by age in the US individuals}

\begin{tabular}{|c|c|c|c|c|c|c|c|}
\hline \multicolumn{4}{|c|}{ GammaGap < $3.65(\mathrm{~g} / \mathrm{dL})$} & \multicolumn{4}{|c|}{ GammaGap $\geq 3.65(\mathrm{~g} / \mathrm{dL})$} \\
\hline Models a & Tertiles of MAMC & $\begin{array}{c}\text { Hazard Ratio } \\
(95 \% \text { CI })\end{array}$ & $P$-value & Models a & Tertiles of MAMC & $\begin{array}{c}\text { Hazard Ratio } \\
(95 \% \text { CI })\end{array}$ & $P$-value \\
\hline \multicolumn{4}{|c|}{ Aged 20-39 years } & \multicolumn{4}{|c|}{ Aged 20-39 years } \\
\hline Model 1 & $\begin{array}{l}\text { T2 v.s. T1 } \\
\text { T3 v.s. T1 }\end{array}$ & $\begin{array}{l}0.86(0.39-1.92) \\
0.60(0.25-1.41)\end{array}$ & $\begin{array}{l}0.721 \\
0.241\end{array}$ & Model 1 & $\begin{array}{l}\text { T2 v.s. T1 } \\
\text { T3 v.s. T1 }\end{array}$ & $\begin{array}{l}1.45(0.36-5.81) \\
1.31(0.29-5.86)\end{array}$ & $\begin{array}{l}0.598 \\
0.726\end{array}$ \\
\hline Model 2 & $\begin{array}{l}\text { T2 v.s. T1 } \\
\text { T3 v.s. T1 }\end{array}$ & $\begin{array}{l}1.16(0.49-2.74) \\
1.11(0.31-3.95)\end{array}$ & $\begin{array}{l}0.740 \\
0.869\end{array}$ & Model 2 & $\begin{array}{l}\text { T2 v.s. T1 } \\
\text { T3 v.s. T1 }\end{array}$ & $\begin{array}{l}1.27(0.30-5.40) \\
1.06(0.14-7.88)\end{array}$ & $\begin{array}{l}0.746 \\
0.954\end{array}$ \\
\hline Model 3 & $\begin{array}{l}\text { T2 v.s. T1 } \\
\text { T3 v.s. T1 }\end{array}$ & $\begin{array}{l}1.28(0.53-3.10) \\
1.39(0.38-5.12)\end{array}$ & $\begin{array}{l}0.587 \\
0.622\end{array}$ & Model 3 & $\begin{array}{l}\text { T2 v.s. T1 } \\
\text { T3 v.s. T1 }\end{array}$ & $\begin{array}{l}1.27(0.29-5.48) \\
1.09(0.15-8.09)\end{array}$ & $\begin{array}{l}0.752 \\
0.935\end{array}$ \\
\hline Model 4 & $\begin{array}{l}\text { T2 v.s. T1 } \\
\text { T3 v.s. T1 }\end{array}$ & $\begin{array}{l}1.28(0.53-3.10) \\
1.39(0.38-5.14)\end{array}$ & $\begin{array}{l}0.586 \\
0.621\end{array}$ & Model 4 & $\begin{array}{l}\text { T2 v.s. T1 } \\
\text { T3 v.s. T1 }\end{array}$ & $\begin{array}{l}1.37(0.32-5.94) \\
1.14(0.16-8.16)\end{array}$ & $\begin{array}{l}0.673 \\
0.897\end{array}$ \\
\hline \multicolumn{4}{|c|}{ Aged 40-59 years } & \multicolumn{4}{|c|}{ Aged 40-59 years } \\
\hline Model 1 & $\begin{array}{l}\text { T2 v.s. T1 } \\
\text { T3 v.s. T1 }\end{array}$ & $\begin{array}{l}1.52(1.02-2.28) \\
1.04(0.69-1.55)\end{array}$ & $\begin{array}{l}0.040 \\
0.863\end{array}$ & Model 1 & $\begin{array}{l}\text { T2 v.s. T1 } \\
\text { T3 v.s. T1 }\end{array}$ & $\begin{array}{l}1.08(0.47-2.45) \\
0.90(0.38-2.12)\end{array}$ & $\begin{array}{l}0.863 \\
0.812\end{array}$ \\
\hline Model 2 & $\begin{array}{l}\text { T2 v.s. T1 } \\
\text { T3 v.s. T1 }\end{array}$ & $\begin{array}{l}1.14(0.72-1.80) \\
0.72(0.41-1.25)\end{array}$ & $\begin{array}{l}0.569 \\
0.240\end{array}$ & Model 2 & $\begin{array}{l}\text { T2 v.s. T1 } \\
\text { T3 v.s. T1 }\end{array}$ & $\begin{array}{l}0.86(0.35-2.11) \\
0.53(0.18-1.58)\end{array}$ & $\begin{array}{l}0.742 \\
0.255\end{array}$ \\
\hline Model 3 & $\begin{array}{l}\text { T2 v.s. T1 } \\
\text { T3 v.s. T1 }\end{array}$ & $\begin{array}{l}1.16(0.74-1.84) \\
0.75(0.43-1.32)\end{array}$ & $\begin{array}{l}0.519 \\
0.320\end{array}$ & Model 3 & $\begin{array}{l}\text { T2 v.s. T1 } \\
\text { T3 v.s. T1 }\end{array}$ & $\begin{array}{l}0.98(0.39-2.47) \\
0.67(0.22-2.00)\end{array}$ & $\begin{array}{l}0.960 \\
0.468\end{array}$ \\
\hline Model 4 & $\begin{array}{l}\text { T2 v.s. T1 } \\
\text { T3 v.s. T1 }\end{array}$ & $\begin{array}{l}1.17(0.74-1.85) \\
0.76(0.44-1.34)\end{array}$ & $\begin{array}{l}0.495 \\
0.346\end{array}$ & Model 4 & $\begin{array}{l}\text { T2 v.s. T1 } \\
\text { T3 v.s. T1 }\end{array}$ & $\begin{array}{l}1.08(0.42-2.79) \\
0.67(0.22-2.05)\end{array}$ & $\begin{array}{l}0.873 \\
0.482\end{array}$ \\
\hline \multicolumn{4}{|c|}{ Aged 60-90 years } & \multicolumn{4}{|c|}{ Aged 60-90 years } \\
\hline Model 1 & $\begin{array}{l}\text { T2 v.s. T1 } \\
\text { T3 v.s. T1 }\end{array}$ & $\begin{array}{l}1.54(1.20-1.96) \\
1.34(1.03-1.73)\end{array}$ & $\begin{array}{l}0.001 \\
0.028\end{array}$ & Model 1 & $\begin{array}{l}\text { T2 v.s. T1 } \\
\text { T3 v.s. T1 }\end{array}$ & $\begin{array}{l}1.09(0.73-1.64) \\
1.17(0.76-1.78)\end{array}$ & $\begin{array}{l}0.678 \\
0.472\end{array}$ \\
\hline Model 2 & $\begin{array}{l}\text { T2 v.s. T1 } \\
\text { T3 v.s. T1 }\end{array}$ & $\begin{array}{l}1.11(0.85-1.46) \\
0.90(0.65-1.25)\end{array}$ & $\begin{array}{l}0.448 \\
0.521\end{array}$ & Model 2 & $\begin{array}{l}\text { T2 v.s. T1 } \\
\text { T3 v.s. T1 }\end{array}$ & $\begin{array}{l}0.60(0.38-0.95) \\
0.49(0.29-0.83)\end{array}$ & $\begin{array}{l}0.028 \\
0.008\end{array}$ \\
\hline Model 3 & $\begin{array}{l}\text { T2 v.s. T1 } \\
\text { T3 v.s. T1 }\end{array}$ & $\begin{array}{l}1.11(0.84-1.46) \\
0.90(0.64-1.25)\end{array}$ & $\begin{array}{l}0.457 \\
0.517\end{array}$ & Model 3 & $\begin{array}{l}\text { T2 v.s. T1 } \\
\text { T3 v.s. T1 }\end{array}$ & $\begin{array}{l}0.66(0.42-1.04) \\
0.53(0.31-0.88)\end{array}$ & $\begin{array}{l}0.073 \\
0.015\end{array}$ \\
\hline Model 4 & $\begin{array}{l}\text { T2 v.s. T1 } \\
\text { T3 v.s. T1 }\end{array}$ & $\begin{array}{l}1.11(0.84-1.47) \\
0.87(0.62-1.21)\end{array}$ & $\begin{array}{l}0.446 \\
0.404\end{array}$ & Model 4 & $\begin{array}{l}\text { T2 v.s. T1 } \\
\text { T3 v.s. T1 }\end{array}$ & $\begin{array}{l}0.66(0.42-1.04) \\
0.57(0.33-0.96)\end{array}$ & $\begin{array}{l}0.076 \\
0.036\end{array}$ \\
\hline
\end{tabular}

${ }^{a}$ Adjusted covariates:

Model 1 = Unadjusted.

Model $2=$ Model $1+$ gender, race and body mass index (BMI).

Model 3 = Model $2+$ serum high-density lipoprotein (HDL), serum fasting glucose, serum total cholesterol, serum total bilirubin, serum aspartate aminotransferase (AST).

Model 4 = Model $3+$ history of congestive heart failure (CHF), stroke, malignancy and smoking.

results [36, 37]. Generally, men have higher muscle mass and muscle capacity than women due to hormone effects, such as much higher levels of testosterone in men. Males also have greater muscle strength and higher physical performance than females [36, 37].

The study does have a number of caveats. First, NHANES III is a study with single measurement of MAMC during the follow-up period, which may engender biased results. The present study is only having exposure data available at one time point, future work should investigate how altered elevated gamma gap and MAMC influences mortality. Second, a myriad of the clinical factors used in the investigation are based on household claimed data that may not be completely accurate. Third, despite adjustments having been made for a large number of potentially confounding factors, unmeasured confounders of the association between MAMC and cause specific mortalities in US individuals cannot be ruled out.

Despite the aforementioned limitations, the present study corroborates previous work demonstrating an positive correlation between all-cause mortality, cancer 

Table 6: Cox proportional hazards regression of cancer mortality for mid-arm muscle circumference
stratified by body mass index (BMI) in the US individuals

\begin{tabular}{|c|c|c|c|c|c|c|c|}
\hline \multicolumn{4}{|c|}{ GammaGap < $3.65(\mathrm{~g} / \mathrm{dL})$} & \multicolumn{4}{|c|}{ GammaGap $\geq 3.65(\mathrm{~g} / \mathrm{dL})$} \\
\hline Models a & Tertiles of MAMC & $\begin{array}{c}\text { Hazard Ratio } \\
(95 \% \text { CI })\end{array}$ & $P$-value & $\underset{\mathrm{a}}{\text { Models }}$ & Tertiles of MAMC & $\begin{array}{c}\text { Hazard Ratio } \\
(95 \% \text { CI })\end{array}$ & $P$-value \\
\hline \multicolumn{4}{|c|}{ BMI 19-24.9 $\left(\mathrm{kg} / \mathrm{m}^{2}\right)$} & \multicolumn{4}{|c|}{ BMI 19-24.9 (kg/m²) } \\
\hline Model 1 & $\begin{array}{l}\text { T2 v.s. T1 } \\
\text { T3 v.s. T1 }\end{array}$ & $\begin{array}{l}1.67(1.27-2.20) \\
0.91(0.61-1.34)\end{array}$ & $\begin{array}{c}<0.001 \\
0.630\end{array}$ & Model 1 & $\begin{array}{l}\text { T2 v.s. T1 } \\
\text { T3 v.s. T1 }\end{array}$ & $\begin{array}{l}2.06(1.24-3.42) \\
1.09(0.53-2.21)\end{array}$ & $\begin{array}{l}0.005 \\
0.816\end{array}$ \\
\hline Model 2 & $\begin{array}{l}\text { T2 v.s. T1 } \\
\text { T3 v.s. T1 }\end{array}$ & $\begin{array}{l}0.95(0.63-1.43) \\
0.94(0.55-1.61)\end{array}$ & $\begin{array}{l}0.815 \\
0.825\end{array}$ & Model 2 & $\begin{array}{l}\text { T2 v.s. T1 } \\
\text { T3 v.s. T1 }\end{array}$ & $\begin{array}{l}0.30(0.15-0.63) \\
0.27(0.11-0.69)\end{array}$ & $\begin{array}{l}0.001 \\
0.006\end{array}$ \\
\hline Model 3 & $\begin{array}{l}\text { T2 v.s. T1 } \\
\text { T3 v.s. T1 }\end{array}$ & $\begin{array}{l}0.99(0.66-1.48) \\
1.01(0.59-1.72)\end{array}$ & $\begin{array}{l}0.961 \\
0.985\end{array}$ & Model 3 & $\begin{array}{l}\text { T2 v.s. T1 } \\
\text { T3 v.s. T1 }\end{array}$ & $\begin{array}{l}0.29(0.13-0.61) \\
0.26(0.10-0.66)\end{array}$ & $\begin{array}{l}0.001 \\
0.005\end{array}$ \\
\hline Model 4 & $\begin{array}{l}\text { T2 v.s. T1 } \\
\text { T3 v.s. T1 }\end{array}$ & $\begin{array}{l}1.00(0.66-1.51) \\
0.99(0.58-1.70)\end{array}$ & $\begin{array}{l}0.995 \\
0.973\end{array}$ & Model 4 & $\begin{array}{l}\text { T2 v.s. T1 } \\
\text { T3 v.s. T1 }\end{array}$ & $\begin{array}{l}0.29(0.13-0.63) \\
0.24(0.09-0.63)\end{array}$ & $\begin{array}{l}0.002 \\
0.004\end{array}$ \\
\hline \multicolumn{4}{|c|}{ BMI 25-29.9 $\left(\mathrm{kg} / \mathrm{m}^{2}\right)$} & \multicolumn{4}{|c|}{ BMI 25-29.9 $\left(\mathrm{kg} / \mathrm{m}^{2}\right)$} \\
\hline Model 1 & $\begin{array}{l}\text { T2 v.s. T1 } \\
\text { T3 v.s. T1 }\end{array}$ & $\begin{array}{l}2.45(1.72-3.51) \\
1.23(0.85-1.77)\end{array}$ & $\begin{array}{c}<0.001 \\
0.278\end{array}$ & Model 1 & $\begin{array}{l}\text { T2 v.s. T1 } \\
\text { T3 v.s. T1 }\end{array}$ & $\begin{array}{l}2.14(1.17-3.92) \\
2.21(1.20-4.07)\end{array}$ & $\begin{array}{l}0.013 \\
0.011\end{array}$ \\
\hline Model 2 & $\begin{array}{l}\text { T2 v.s. T1 } \\
\text { T3 v.s. T1 }\end{array}$ & $\begin{array}{l}1.20(0.80-1.79) \\
0.69(0.42-1.13)\end{array}$ & $\begin{array}{l}0.372 \\
0.138\end{array}$ & Model 2 & $\begin{array}{l}\text { T2 v.s. T1 } \\
\text { T3 v.s. T1 }\end{array}$ & $\begin{array}{l}0.74(0.36-1.51) \\
0.66(0.28-1.57)\end{array}$ & $\begin{array}{l}0.406 \\
0.352\end{array}$ \\
\hline Model 3 & $\begin{array}{l}\text { T2 v.s. T1 } \\
\text { T3 v.s. T1 }\end{array}$ & $\begin{array}{l}1.24(0.83-1.84) \\
0.73(0.45-1.19)\end{array}$ & $\begin{array}{l}0.289 \\
0.210\end{array}$ & Model 3 & $\begin{array}{l}\text { T2 v.s. T1 } \\
\text { T3 v.s. T1 }\end{array}$ & $\begin{array}{l}0.77(0.39-1.53) \\
0.64(0.28-1.48)\end{array}$ & $\begin{array}{l}0.458 \\
0.300\end{array}$ \\
\hline Model 4 & $\begin{array}{l}\text { T2 v.s. T1 } \\
\text { T3 v.s. T1 }\end{array}$ & $\begin{array}{l}1.22(0.82-1.82) \\
0.69(0.42-1.13)\end{array}$ & $\begin{array}{l}0.330 \\
0.140\end{array}$ & Model 4 & $\begin{array}{l}\text { T2 v.s. T1 } \\
\text { T3 v.s. T1 }\end{array}$ & $\begin{array}{l}0.77(0.39-1.55) \\
0.66(0.28-1.52)\end{array}$ & $\begin{array}{l}0.467 \\
0.327\end{array}$ \\
\hline \multicolumn{4}{|c|}{$\mathrm{BMI} \geq 30\left(\mathrm{~kg} / \mathrm{m}^{2}\right)$} & \multicolumn{4}{|c|}{$\mathrm{BMI} \geq 30\left(\mathrm{~kg} / \mathrm{m}^{2}\right)$} \\
\hline Model 1 & $\begin{array}{l}\text { T2 v.s. T1 } \\
\text { T3 v.s. T1 }\end{array}$ & $\begin{array}{l}1.65(0.80-3.38) \\
2.10(1.05-4.18)\end{array}$ & $\begin{array}{l}0.172 \\
0.035\end{array}$ & Model 1 & $\begin{array}{l}\text { T2 v.s. T1 } \\
\text { T3 v.s. T1 }\end{array}$ & $\begin{array}{c}2.46(0.73-8.24) \\
3.04(0.92-10.04)\end{array}$ & $\begin{array}{l}0.145 \\
0.068\end{array}$ \\
\hline Model 2 & $\begin{array}{l}\text { T2 v.s. T1 } \\
\text { T3 v.s. T1 }\end{array}$ & $\begin{array}{l}1.52(0.74-3.12) \\
1.59(0.73-3.48)\end{array}$ & $\begin{array}{l}0.258 \\
0.246\end{array}$ & Model 2 & $\begin{array}{l}\text { T2 v.s. T1 } \\
\text { T3 v.s. T1 }\end{array}$ & $\begin{array}{l}1.32(0.39-4.48) \\
1.38(0.39-4.96)\end{array}$ & $\begin{array}{l}0.654 \\
0.618\end{array}$ \\
\hline Model 3 & $\begin{array}{l}\text { T2 v.s. T1 } \\
\text { T3 v.s. T1 }\end{array}$ & $\begin{array}{l}1.50(0.73-3.09) \\
1.48(0.68-3.23)\end{array}$ & $\begin{array}{l}0.272 \\
0.324\end{array}$ & Model 3 & $\begin{array}{l}\text { T2 v.s. T1 } \\
\text { T3 v.s. T1 }\end{array}$ & $\begin{array}{l}1.36(0.40-4.65) \\
1.33(0.37-4.78)\end{array}$ & $\begin{array}{l}0.624 \\
0.659\end{array}$ \\
\hline Model 4 & $\begin{array}{l}\text { T2 v.s. T1 } \\
\text { T3 v.s. T1 }\end{array}$ & $\begin{array}{l}1.51(0.73-3.12) \\
1.46(0.67-3.19)\end{array}$ & $\begin{array}{l}0.261 \\
0.345\end{array}$ & Model 4 & $\begin{array}{l}\text { T2 v.s. T1 } \\
\text { T3 v.s. T1 }\end{array}$ & $\begin{array}{l}1.21(0.35-4.21) \\
1.33(0.37-4.77)\end{array}$ & $\begin{array}{l}0.766 \\
0.666\end{array}$ \\
\hline
\end{tabular}

${ }^{a}$ Adjusted covariates:

Model 1 = Unadjusted.

Model $2=$ Model $1+$ age, gender, and race.

Model 3 = Model $2+$ serum high-density lipoprotein (HDL), serum fasting glucose, serum total cholesterol, serum total bilirubin, serum aspartate aminotransferase (AST).

Model 4 = Model $3+$ history of congestive heart failure (CHF), stroke, malignancy and smoking.

mortality, CV mortality and those with gamma gap $\geq 3.65 \mathrm{~g} / \mathrm{dl}$, also providing evidence supporting the protective effect of higher MAMC on mortality among individuals with an elevated gamma gap. Future work may benefit by examining the extent to which changes in MAMC influence mortality risk among people with an elevated gamma gap. Future work would also benefit by applying our findings to clinical and epidemiological investigations.

\section{MATERIALS AND METHODS}

\section{Data source and participants}

Data were retrieved from the NHANES III (19881994), a cross-sectional survey designed to evaluate the health and nutritional status of the noninstitutionalized U.S. adults by the National Center for Health Statistics (NCHS) of the Centers for Disease Control and Prevention 
Table 7: Cox proportional hazards regression of cancer mortality for mid-arm muscle circumference stratified by gender in the US individuals

\begin{tabular}{|c|c|c|c|c|c|c|c|}
\hline \multicolumn{4}{|c|}{ GammaGap < $3.65(\mathrm{~g} / \mathrm{dL})$} & \multicolumn{4}{|c|}{ GammaGap $\geq 3.65(\mathrm{~g} / \mathrm{dL})$} \\
\hline Models $^{\mathbf{a}}$ & $\begin{array}{l}\text { Tertiles of } \\
\text { MAMC }\end{array}$ & $\begin{array}{c}\text { Hazard Ratio }(95 \% \\
\text { CI) }\end{array}$ & $P$-value & Models a & $\begin{array}{c}\text { Tertiles of } \\
\text { MAMC }\end{array}$ & Hazard Ratio (95\% CI) & $P$-value \\
\hline \multicolumn{4}{|c|}{ Male } & \multicolumn{4}{|c|}{ Male } \\
\hline Model 1 & $\begin{array}{l}\text { T2 v.s. T1 } \\
\text { T3 v.s. T1 }\end{array}$ & $\begin{array}{l}0.59(0.37-0.96) \\
0.33(0.21-0.53)\end{array}$ & $\begin{array}{c}0.032 \\
<0.001\end{array}$ & Model 1 & $\begin{array}{l}\text { T2 v.s. T1 } \\
\text { T3 v.s. T1 }\end{array}$ & $\begin{array}{l}0.39(0.21-0.73) \\
0.15(0.08-0.29)\end{array}$ & $\begin{array}{c}0.003 \\
<0.001\end{array}$ \\
\hline Model 2 & $\begin{array}{l}\text { T2 v.s. T1 } \\
\text { T3 v.s. T1 }\end{array}$ & $\begin{array}{l}0.94(0.58-1.51) \\
0.69(0.43-1.12)\end{array}$ & $\begin{array}{l}0.793 \\
0.130\end{array}$ & Model 2 & $\begin{array}{l}\text { T2 v.s. T1 } \\
\text { T3 v.s. T1 }\end{array}$ & $\begin{array}{l}0.37(0.20-0.70) \\
0.26(0.13-0.50)\end{array}$ & $\begin{array}{c}0.002 \\
<0.001\end{array}$ \\
\hline Model 3 & $\begin{array}{l}\text { T2 v.s. T1 } \\
\text { T3 v.s. T1 }\end{array}$ & $\begin{array}{l}1.03(0.64-1.67) \\
0.78(0.48-1.26)\end{array}$ & $\begin{array}{l}0.903 \\
0.309\end{array}$ & Model 3 & $\begin{array}{l}\text { T2 v.s. T1 } \\
\text { T3 v.s. T1 }\end{array}$ & $\begin{array}{l}0.46(0.23-0.92) \\
0.32(0.15-0.65)\end{array}$ & $\begin{array}{l}0.027 \\
0.002\end{array}$ \\
\hline Model 4 & $\begin{array}{l}\text { T2 v.s. T1 } \\
\text { T3 v.s. T1 }\end{array}$ & $\begin{array}{l}1.01(0.62-1.63) \\
0.74(0.46-1.21)\end{array}$ & $\begin{array}{l}0.975 \\
0.233\end{array}$ & Model 4 & $\begin{array}{l}\text { T2 v.s. T1 } \\
\text { T3 v.s. T1 }\end{array}$ & $\begin{array}{l}0.44(0.22-0.88) \\
0.32(0.15-0.67)\end{array}$ & $\begin{array}{l}0.021 \\
0.002\end{array}$ \\
\hline \multicolumn{4}{|c|}{ Female } & \multicolumn{4}{|c|}{ Female } \\
\hline Model 1 & $\begin{array}{l}\text { T2 v.s. T1 } \\
\text { T3 v.s. T1 }\end{array}$ & $\begin{array}{l}1.57(1.22-2.04) \\
1.41(0.86-2.31)\end{array}$ & $\begin{array}{l}0.001 \\
0.169\end{array}$ & Model 1 & $\begin{array}{l}\text { T2 v.s. T1 } \\
\text { T3 v.s. T1 }\end{array}$ & $\begin{array}{l}1.02(0.62-1.66) \\
1.76(0.96-3.25)\end{array}$ & $\begin{array}{l}0.952 \\
0.069\end{array}$ \\
\hline Model 2 & $\begin{array}{l}\text { T2 v.s. T1 } \\
\text { T3 v.s. T1 }\end{array}$ & $\begin{array}{l}1.14(0.88-1.48) \\
1.14(0.70-1.87)\end{array}$ & $\begin{array}{l}0.320 \\
0.597\end{array}$ & Model 2 & $\begin{array}{l}\text { T2 v.s. T1 } \\
\text { T3 v.s. T1 }\end{array}$ & $\begin{array}{l}0.74(0.45-1.22) \\
1.32(0.72-2.43)\end{array}$ & $\begin{array}{l}0.236 \\
0.376\end{array}$ \\
\hline Model 3 & $\begin{array}{l}\text { T2 v.s. T1 } \\
\text { T3 v.s. T1 }\end{array}$ & $\begin{array}{l}1.13(0.87-1.46) \\
1.08(0.66-1.78)\end{array}$ & $\begin{array}{l}0.375 \\
0.757\end{array}$ & Model 3 & $\begin{array}{l}\text { T2 v.s. T1 } \\
\text { T3 v.s. T1 }\end{array}$ & $\begin{array}{l}0.74(0.45-1.22) \\
1.37(0.74-2.54)\end{array}$ & $\begin{array}{l}0.239 \\
0.320\end{array}$ \\
\hline Model 4 & $\begin{array}{l}\text { T2 v.s. T1 } \\
\text { T3 v.s. T1 }\end{array}$ & $\begin{array}{l}1.13(0.87-1.47) \\
1.08(0.65-1.77)\end{array}$ & $\begin{array}{l}0.345 \\
0.773\end{array}$ & Model 4 & $\begin{array}{l}\text { T2 v.s. T1 } \\
\text { T3 v.s. T1 }\end{array}$ & $\begin{array}{l}0.73(0.44-1.22) \\
1.42(0.76-2.64)\end{array}$ & $\begin{array}{l}0.231 \\
0.273\end{array}$ \\
\hline
\end{tabular}

a Adjusted covariates:

Model 1 = Unadjusted.

Model 2 = Model $1+$ age, race and body mass index (BMI).

Model 3 = Model $2+$ serum high-density lipoprotein (HDL), serum fasting glucose, serum total cholesterol , serum total bilirubin, serum aspartate aminotransferase (AST).

Model 4 = Model $3+$ history of congestive heart failure (CHF), stroke, malignancy and smoking.

(CDC) [38]. Approved by Institutional Review Board (IRB), NHANES III comprised household interviews and physical examinations conducted at mobile examination centers. The NHANES III survey was based on a complex, multistage, stratified and clustered design and was executed in accordance with the Declaration of Helsinki. We selected adults between 20 to 90 years of age in the NHANES III to performed the present study, and these participants were involved with a mean follow-up of 14.3 years.

\section{Follow-up data on all-cause mortality, cancer mortality, and cardiovascular mortality}

NCHS linked NHANES III survey to death certificate records with the National Death Index (NDI), a computerized database of all certified deaths in the U.S. since 1979 [39]. Linkage of the NHANES III participants with the NDI mortality data provided the opportunity to conduct a vast array of outcome surveys designed to investigate the correlation of health factors with mortality. This file linked NHANES III participants with death records from the NDI through 31 December 2006. The cause of death was coded using the International
Classification of Disease (ICD)-9 until 1998 and ICD10 was used from 1999 onward. To adjust for changes between the two coding systems, final cause of deaths occurring prior to 1999 were re-coded into comparable ICD-10-based underlying cause of death groups [40]. For overall mortality, we included deaths from all causes; for cancer-specific mortality, we included deaths from malignant neoplasms (ICD-10 = C00-C97); for CV diseases related mortality, we included diseases of the heart and circulation system (ICD-10 $=\mathrm{I} 00-\mathrm{I} 178$ ).

\section{Measurement: gamma gap}

According to the original protocol, NHANES III collected a comprehensive serum metabolic data form the participants. The analyses were using the Hitachi Model 704 multichannel analyzer. The NHANES personnel evaluated total protein with a colorimetric assay, while albumin was determined via a Bromocresol purple reagent. Gamma gap was calculated with the following formula: serum total protein $(\mathrm{g} / \mathrm{dl})$-serum albumin $(\mathrm{g} / \mathrm{dl})$. In clinical practice, the threshold of gamma gap was $3.5 \mathrm{~g} / \mathrm{dl}$ or $4.0 \mathrm{~g} /$ dl [1]. We conducted the ROC curve for gamma gap. The area under the curve (AUC) was an index of the ability of 

Table 8: Cox proportional hazards regression of cardiovascular mortality for mid-arm muscle
circumference stratified by age in the US individuals

\begin{tabular}{|c|c|c|c|c|c|c|c|}
\hline \multicolumn{4}{|c|}{ GammaGap $<3.65(\mathrm{~g} / \mathrm{dL})$} & \multicolumn{4}{|c|}{ GammaGap $\geq 3.65(\mathrm{~g} / \mathrm{dL})$} \\
\hline Models a & Tertiles of MAMC & $\begin{array}{c}\text { Hazard Ratio } \\
(95 \% \text { CI) }\end{array}$ & $\begin{array}{c}P \\
\text {-value }\end{array}$ & Models a & Tertiles of MAMC & $\begin{array}{c}\text { Hazard Ratio } \\
(95 \% \text { CI) }\end{array}$ & $P$-value \\
\hline \multicolumn{4}{|c|}{ Aged 20-39 years } & \multicolumn{4}{|c|}{ Aged 20-39 years } \\
\hline Model 1 & $\begin{array}{l}\text { T2 v.s. T1 } \\
\text { T3 v.s. T1 }\end{array}$ & $\begin{array}{c}5.75(1.24-26.60) \\
10.56(2.46-45.33)\end{array}$ & $\begin{array}{l}0.025 \\
0.002\end{array}$ & Model 1 & $\begin{array}{l}\text { T2 v.s. T1 } \\
\text { T3 v.s. T1 }\end{array}$ & $\begin{array}{c}0.97(0.16-5.83) \\
3.22(0.81-12.89)\end{array}$ & $\begin{array}{l}0.977 \\
0.098\end{array}$ \\
\hline Model 2 & $\begin{array}{l}\text { T2 v.s. T1 } \\
\text { T3 v.s. T1 }\end{array}$ & $\begin{array}{c}7.22(1.48-35.31) \\
16.46(3-90.26 .00)\end{array}$ & $\begin{array}{l}0.015 \\
0.001\end{array}$ & Model 2 & $\begin{array}{l}\text { T2 v.s. T1 } \\
\text { T3 v.s. T1 }\end{array}$ & $\begin{array}{l}0.37(0.04-3.49) \\
0.52(0.04-6.08)\end{array}$ & $\begin{array}{l}0.388 \\
0.600\end{array}$ \\
\hline Model 3 & $\begin{array}{l}\text { T2 v.s. T1 } \\
\text { T3 v.s. T1 }\end{array}$ & $\begin{array}{c}6.92(1.4-34.17) \\
14.39(2.55-81.08)\end{array}$ & $\begin{array}{l}0.018 \\
0.003\end{array}$ & Model 3 & $\begin{array}{l}\text { T2 v.s. T1 } \\
\text { T3 v.s. T1 }\end{array}$ & $\begin{array}{l}0.44(0.04-4.31) \\
0.54(0.04-6.66)\end{array}$ & $\begin{array}{l}0.481 \\
0.634\end{array}$ \\
\hline Model 4 & $\begin{array}{l}\text { T2 v.s. T1 } \\
\text { T3 v.s. T1 }\end{array}$ & $\begin{array}{c}6.98(1.41-34.42) \\
14.08(2.49-79.55)\end{array}$ & $\begin{array}{l}0.017 \\
0.003\end{array}$ & Model 4 & $\begin{array}{l}\text { T2 v.s. T1 } \\
\text { T3 v.s. T1 }\end{array}$ & $\begin{array}{l}0.39(0.04-3.87) \\
0.39(0.03-5.83)\end{array}$ & $\begin{array}{l}0.420 \\
0.495\end{array}$ \\
\hline \multicolumn{4}{|c|}{ Aged 40-59 years } & \multicolumn{4}{|c|}{ Aged 40-59 years } \\
\hline Model 1 & $\begin{array}{l}\text { T2 v.s. T1 } \\
\text { T3 v.s. T1 }\end{array}$ & $\begin{array}{l}2.19(1.28-3.72) \\
2.28(1.38-3.78)\end{array}$ & $\begin{array}{l}0.004 \\
0.001\end{array}$ & Model 1 & $\begin{array}{l}\text { T2 v.s. T1 } \\
\text { T3 v.s. T1 }\end{array}$ & $\begin{array}{l}1.73(0.78-3.83) \\
2.00(0.93-4.33)\end{array}$ & $\begin{array}{l}0.175 \\
0.077\end{array}$ \\
\hline Model 2 & $\begin{array}{l}\text { T2 v.s. T1 } \\
\text { T3 v.s. T1 }\end{array}$ & $\begin{array}{l}1.46(0.80-2.67) \\
1.27(0.64-2.50)\end{array}$ & $\begin{array}{l}0.214 \\
0.494\end{array}$ & Model 2 & $\begin{array}{l}\text { T2 v.s. T1 } \\
\text { T3 v.s. T1 }\end{array}$ & $\begin{array}{l}1.39(0.60-3.21) \\
1.13(0.44-2.91)\end{array}$ & $\begin{array}{l}0.445 \\
0.805\end{array}$ \\
\hline Model 3 & $\begin{array}{l}\text { T2 v.s. T1 } \\
\text { T3 v.s. T1 }\end{array}$ & $\begin{array}{l}1.47(0.81-2.69) \\
1.28(0.64-2.53)\end{array}$ & $\begin{array}{l}0.209 \\
0.484\end{array}$ & Model 3 & $\begin{array}{l}\text { T2 v.s. T1 } \\
\text { T3 v.s. T1 }\end{array}$ & $\begin{array}{l}1.32(0.56-3.07) \\
1.13(0.43-2.97)\end{array}$ & $\begin{array}{l}0.525 \\
0.807\end{array}$ \\
\hline Model 4 & $\begin{array}{l}\text { T2 v.s. T1 } \\
\text { T3 v.s. T1 }\end{array}$ & $\begin{array}{l}1.41(0.77-2.58) \\
1.19(0.60-2.37)\end{array}$ & $\begin{array}{l}0.268 \\
0.613\end{array}$ & Model 4 & $\begin{array}{l}\text { T2 v.s. T1 } \\
\text { T3 v.s. T1 }\end{array}$ & $\begin{array}{l}1.13(0.48-2.69) \\
1.05(0.39-2.84)\end{array}$ & $\begin{array}{l}0.774 \\
0.927\end{array}$ \\
\hline \multicolumn{4}{|c|}{ Aged 60-90 years } & \multicolumn{4}{|c|}{ Aged 60-90 years } \\
\hline Model 1 & $\begin{array}{l}\text { T2 v.s. T1 } \\
\text { T3 v.s. T1 }\end{array}$ & $\begin{array}{l}1.20(1.03-1.38) \\
0.85(0.72-1.00)\end{array}$ & $\begin{array}{l}0.016 \\
0.054\end{array}$ & Model 1 & $\begin{array}{l}\text { T2 v.s. T1 } \\
\text { T3 v.s. T1 }\end{array}$ & $\begin{array}{l}0.81(0.61-1.07) \\
0.76(0.56-1.04)\end{array}$ & $\begin{array}{l}0.136 \\
0.089\end{array}$ \\
\hline Model 2 & $\begin{array}{l}\text { T2 v.s. T1 } \\
\text { T3 v.s. T1 }\end{array}$ & $\begin{array}{l}1.07(0.91-1.25) \\
0.99(0.80-1.22)\end{array}$ & $\begin{array}{l}0.443 \\
0.913\end{array}$ & Model 2 & $\begin{array}{l}\text { T2 v.s. T1 } \\
\text { T3 v.s. T1 }\end{array}$ & $\begin{array}{l}0.68(0.50-0.92) \\
0.65(0.44-0.94)\end{array}$ & $\begin{array}{l}0.012 \\
0.022\end{array}$ \\
\hline Model 3 & $\begin{array}{l}\text { T2 v.s. T1 } \\
\text { T3 v.s. T1 }\end{array}$ & $\begin{array}{l}1.05(0.89-1.24) \\
0.97(0.78-1.20)\end{array}$ & $\begin{array}{l}0.547 \\
0.770\end{array}$ & Model 3 & $\begin{array}{l}\text { T2 v.s. T1 } \\
\text { T3 v.s. T1 }\end{array}$ & $\begin{array}{l}0.68(0.50-0.92) \\
0.62(0.42-0.91)\end{array}$ & $\begin{array}{l}0.013 \\
0.013\end{array}$ \\
\hline Model 4 & $\begin{array}{l}\text { T2 v.s. T1 } \\
\text { T3 v.s. T1 }\end{array}$ & $\begin{array}{l}1.06(0.90-1.25) \\
0.97(0.78-1.20)\end{array}$ & $\begin{array}{l}0.486 \\
0.750\end{array}$ & Model 4 & $\begin{array}{l}\text { T2 v.s. T1 } \\
\text { T3 v.s. T1 }\end{array}$ & $\begin{array}{l}0.67(0.49-0.91) \\
0.62(0.42-0.91)\end{array}$ & $\begin{array}{l}0.011 \\
0.014\end{array}$ \\
\hline
\end{tabular}

${ }^{a}$ Adjusted covariates:

Model 1 = Unadjusted.

Model 2 = Model $1+$ gender, race and body mass index (BMI).

Model 3 = Model $2+$ serum high-density lipoprotein (HDL), serum fasting glucose, serum total cholesterol, serum total bilirubin, serum aspartate aminotransferase (AST).

Model 4 = Model $3+$ history of congestive heart failure (CHF), stroke, malignancy and smoking.

a marker to discriminate between true positives and true negatives. In the present study, an elevated gamma gap was defined using the cut-point of $\geq 3.65 \mathrm{~g} / \mathrm{dl}$.

\section{Measurement: anthropometric parameters}

The anthropometric parameters were undertaken using a standard protocol and collection instruments as outlined below. Body height and weight were measured, and converted to BMI in units of $\mathrm{kg} / \mathrm{m}^{2}$. Have the participants standing upright with relaxed shoulder, and marked at the midpoint posteriorly to the upper arm. Then placed a tape measure around the target point and pressed to the skin surface without tight compress. The operator measured the circumference of the upper arm vertically to the long axis of it. The MAC value was measured to the nearest $0.1 \mathrm{~cm}$. To measure the TS, the operator grasped about $2.0 \mathrm{~cm}$ of the TS above the marked point and kept the jaws of the skinfold calipers vertically to the shaft of the arm over the marked point. The TS value was recorded to the nearest $0.1 \mathrm{~mm}$. MAMC $(\mathrm{cm})$, an established measure of muscle protein mass, was calculated as: MAC $(\mathrm{cm})-0.3142 \times$ TS thickness $(\mathrm{mm})$.

\section{Definition of the MAMC tertiles group}

We categorized both male and female participants into tertiles based on their MAMC level. The participants 


\section{Table 9: Cox proportional hazards regression of cardiovascular mortality for mid-arm muscle circumference stratified by body mass index (BMI) in the US individuals}

\begin{tabular}{|c|c|c|c|c|c|c|c|}
\hline \multicolumn{4}{|c|}{ GammaGap $<3.65(\mathrm{~g} / \mathrm{dL})$} & \multicolumn{4}{|c|}{ GammaGap $\geq 3.65(\mathrm{~g} / \mathrm{dL})$} \\
\hline Models a & Tertiles of MAMC & $\begin{array}{l}\text { Hazard Ratio } \\
\quad(95 \% \mathrm{CI})\end{array}$ & $P$-value & Models a & Tertiles of MAMC & $\begin{array}{c}\text { Hazard Ratio } \\
(95 \% \text { CI) }\end{array}$ & $P$-value \\
\hline \multicolumn{4}{|c|}{ BMI 19-24.9 (kg/m²) } & \multicolumn{4}{|c|}{ BMI 19-24.9 (kg/m²) } \\
\hline Model 1 & $\begin{array}{l}\text { T2 v.s. T1 } \\
\text { T3 v.s. T1 }\end{array}$ & $\begin{array}{l}1.62(1.33-1.97) \\
0.48(0.34-0.70)\end{array}$ & $\begin{array}{l}<0.001 \\
<0.001\end{array}$ & Model 1 & $\begin{array}{l}\text { T2 v.s. T1 } \\
\text { T3 v.s. T1 }\end{array}$ & $\begin{array}{l}1.46(0.99-2.16) \\
0.39(0.18-0.86)\end{array}$ & $\begin{array}{l}0.056 \\
0.019\end{array}$ \\
\hline Model 2 & $\begin{array}{l}\text { T2 v.s. T1 } \\
\text { T3 v.s. T1 }\end{array}$ & $\begin{array}{l}1.08(0.84-1.39) \\
0.98(0.64-1.50)\end{array}$ & $\begin{array}{l}0.539 \\
0.913\end{array}$ & Model 2 & $\begin{array}{l}\text { T2 v.s. T1 } \\
\text { T3 v.s. T1 }\end{array}$ & $\begin{array}{l}0.53(0.32-0.90) \\
0.45(0.18-1.15)\end{array}$ & $\begin{array}{l}0.018 \\
0.094\end{array}$ \\
\hline Model 3 & $\begin{array}{l}\text { T2 v.s. T1 } \\
\text { T3 v.s. T1 }\end{array}$ & $\begin{array}{l}1.09(0.85-1.41) \\
1.00(0.65-1.54)\end{array}$ & $\begin{array}{l}0.481 \\
0.993\end{array}$ & Model 3 & $\begin{array}{l}\text { T2 v.s. T1 } \\
\text { T3 v.s. T1 }\end{array}$ & $\begin{array}{l}0.49(0.28-0.84) \\
0.42(0.16-1.07)\end{array}$ & $\begin{array}{l}0.010 \\
0.069\end{array}$ \\
\hline Model 4 & $\begin{array}{l}\text { T2 v.s. T1 } \\
\text { T3 v.s. T1 }\end{array}$ & $\begin{array}{l}1.12(0.87-1.44) \\
1.01(0.65-1.56)\end{array}$ & $\begin{array}{l}0.373 \\
0.964\end{array}$ & Model 4 & $\begin{array}{l}\text { T2 v.s. T1 } \\
\text { T3 v.s. T1 }\end{array}$ & $\begin{array}{l}0.45(0.25-0.80) \\
0.40(0.15-1.05)\end{array}$ & $\begin{array}{l}0.006 \\
0.061\end{array}$ \\
\hline \multicolumn{4}{|c|}{ BMI 25-29.9 (kg/m²) } & \multicolumn{4}{|c|}{ BMI 25-29.9 (kg/m²) } \\
\hline Model 1 & $\begin{array}{l}\text { T2 v.s. T1 } \\
\text { T3 v.s. T1 }\end{array}$ & $\begin{array}{l}2.02(1.58-2.57) \\
0.88(0.68-1.15)\end{array}$ & $\begin{array}{c}<0.001 \\
0.348\end{array}$ & Model 1 & $\begin{array}{l}\text { T2 v.s. T1 } \\
\text { T3 v.s. T1 }\end{array}$ & $\begin{array}{l}1.92(1.20-3.08) \\
1.45(0.87-2.43)\end{array}$ & $\begin{array}{l}0.007 \\
0.153\end{array}$ \\
\hline Model 2 & $\begin{array}{l}\text { T2 v.s. T1 } \\
\text { T3 v.s. T1 }\end{array}$ & $\begin{array}{l}0.94(0.71-1.24) \\
0.78(0.55-1.11)\end{array}$ & $\begin{array}{l}0.674 \\
0.172\end{array}$ & Model 2 & $\begin{array}{l}\text { T2 v.s. T1 } \\
\text { T3 v.s. T1 }\end{array}$ & $\begin{array}{l}0.98(0.58-1.64) \\
0.65(0.32-1.30)\end{array}$ & $\begin{array}{l}0.930 \\
0.224\end{array}$ \\
\hline Model 3 & $\begin{array}{l}\text { T2 v.s. T1 } \\
\text { T3 v.s. T1 }\end{array}$ & $\begin{array}{l}0.94(0.71-1.25) \\
0.78(0.54-1.11)\end{array}$ & $\begin{array}{l}0.680 \\
0.165\end{array}$ & Model 3 & $\begin{array}{l}\text { T2 v.s. T1 } \\
\text { T3 v.s. T1 }\end{array}$ & $\begin{array}{l}0.96(0.57-1.61) \\
0.63(0.31-1.27)\end{array}$ & $\begin{array}{l}0.864 \\
0.200\end{array}$ \\
\hline Model 4 & $\begin{array}{l}\text { T2 v.s. T1 } \\
\text { T3 v.s. T1 }\end{array}$ & $\begin{array}{l}0.92(0.69-1.21) \\
0.75(0.52-1.07)\end{array}$ & $\begin{array}{l}0.543 \\
0.117\end{array}$ & Model 4 & $\begin{array}{l}\text { T2 v.s. T1 } \\
\text { T3 v.s. T1 }\end{array}$ & $\begin{array}{l}0.93(0.55-1.59) \\
0.60(0.29-1.22)\end{array}$ & $\begin{array}{l}0.793 \\
0.156\end{array}$ \\
\hline \multicolumn{4}{|c|}{$B M I \geq 30\left(\mathrm{~kg} / \mathrm{m}^{2}\right)$} & \multicolumn{4}{|c|}{$\mathrm{BMI} \geq 30\left(\mathrm{~kg} / \mathrm{m}^{2}\right)$} \\
\hline Model 1 & $\begin{array}{l}\text { T2 v.s. T1 } \\
\text { T3 v.s. T1 }\end{array}$ & $\begin{array}{l}1.42(0.89-2.26) \\
1.63(1.04-2.54)\end{array}$ & $\begin{array}{l}0.142 \\
0.033\end{array}$ & Model 1 & $\begin{array}{l}\text { T2 v.s. T1 } \\
\text { T3 v.s. T1 }\end{array}$ & $\begin{array}{l}1.47(0.71-3.03) \\
2.20(1.09-4.43)\end{array}$ & $\begin{array}{l}0.302 \\
0.028\end{array}$ \\
\hline Model 2 & $\begin{array}{l}\text { T2 v.s. T1 } \\
\text { T3 v.s. T1 }\end{array}$ & $\begin{array}{l}1.22(0.76-1.95) \\
1.33(0.79-2.22)\end{array}$ & $\begin{array}{l}0.404 \\
0.279\end{array}$ & Model 2 & $\begin{array}{l}\text { T2 v.s. T1 } \\
\text { T3 v.s. T1 }\end{array}$ & $\begin{array}{l}0.81(0.39-1.68) \\
1.07(0.50-2.27)\end{array}$ & $\begin{array}{l}0.571 \\
0.862\end{array}$ \\
\hline Model 3 & $\begin{array}{l}\text { T2 v.s. T1 } \\
\text { T3 v.s. T1 }\end{array}$ & $\begin{array}{l}1.23(0.77-1.98) \\
1.35(0.81-2.25)\end{array}$ & $\begin{array}{l}0.379 \\
0.251\end{array}$ & Model 3 & $\begin{array}{l}\text { T2 v.s. T1 } \\
\text { T3 v.s. T1 }\end{array}$ & $\begin{array}{l}0.89(0.43-1.86) \\
1.10(0.52-2.34)\end{array}$ & $\begin{array}{l}0.761 \\
0.800\end{array}$ \\
\hline Model 4 & $\begin{array}{l}\text { T2 v.s. T1 } \\
\text { T3 v.s. T1 }\end{array}$ & $\begin{array}{l}1.22(0.76-1.95) \\
1.38(0.83-2.31)\end{array}$ & $\begin{array}{l}0.416 \\
0.213\end{array}$ & Model 4 & $\begin{array}{l}\text { T2 v.s. T1 } \\
\text { T3 v.s. T1 }\end{array}$ & $\begin{array}{l}0.95(0.45-2.00) \\
1.34(0.62-2.88)\end{array}$ & $\begin{array}{l}0.895 \\
0.454\end{array}$ \\
\hline
\end{tabular}

${ }^{a}$ Adjusted covariates:

Model 1 = Unadjusted.

Model $2=$ Model $1+$ age, gender, and race.

Model 3 = Model $2+$ serum high-density lipoprotein (HDL), serum fasting glucose, serum total cholesterol, serum total bilirubin, serum aspartate aminotransferase (AST).

Model $4=$ Model $3+$ history of congestive heart failure (CHF), stroke, malignancy and smoking.

in the lowest tertile was defined as the reference group. The gender-specific tertiles were as follows: T1 (15.927.3), T2 (27.4-29.7), T3 (29.8-40.9) $\mathrm{cm}$ in the male group and T1 (13.8-21.9), T2 (22.0-24.2), T3 (24.3-44.1) $\mathrm{cm}$ in the female group.

\section{Measurement: risk variables}

Self-report variables were as the below mentioned: age, gender, ethnicity, smoking status, past medical history diagnosed by a doctor (type 2 DM, skin cancer, other cancer, stroke, CHF, and asthma).
Metabolic variables were obtained from blood samples. The hexokinase enzymatic method was adopted to analyze the plasma glucose according to the Cobas Mira Chemistry System (Roche Diagnostic Systems, Indianapolis, IN, USA). The venipuncture time of the participants was after fasted for 6 hours. Serum TC, serum TG, serum HDL and serum LDL were measured by the Hitachi 704 Analyzer (Roche Diagnostics, Indianapolis, IN, USA). Serum CRP level was measured with latexenhanced nephelometry (Behring Nephelometer II Analyzer System; Behring Diagnostics Inc., Somerville, NJ, USA). The study utilized the Beckman Synchron 


\section{Table 10: Cox proportional hazards regression of cardiovascular mortality for mid-arm muscle circumference stratified by gender in the US individuals}

\begin{tabular}{|c|c|c|c|c|c|c|c|}
\hline \multicolumn{4}{|c|}{ GammaGap < $3.65(\mathrm{~g} / \mathrm{dL})$} & \multicolumn{4}{|c|}{ GammaGap $\geq 3.65(\mathrm{~g} / \mathrm{dL})$} \\
\hline Models a & Tertiles of MAMC & $\begin{array}{c}\text { Hazard Ratio } \\
(95 \% \text { CI })\end{array}$ & $P$-value & Models a & Tertiles of MAMC & $\begin{array}{l}\text { Hazard Ratio } \\
(95 \% \text { CI })\end{array}$ & $P$-value \\
\hline \multicolumn{4}{|c|}{ Male } & \multicolumn{4}{|c|}{ Male } \\
\hline Model 1 & $\begin{array}{l}\text { T2 v.s. T1 } \\
\text { T3 v.s. T1 }\end{array}$ & $\begin{array}{l}0.46(0.34-0.61) \\
0.20(0.15-0.27)\end{array}$ & $\begin{array}{l}<0.001 \\
<0.001\end{array}$ & Model 1 & $\begin{array}{l}\text { T2 v.s. T1 } \\
\text { T3 v.s. T1 }\end{array}$ & $\begin{array}{l}0.40(0.24-0.67) \\
0.17(0.10-0.28)\end{array}$ & $\begin{array}{l}<0.001 \\
<0.001\end{array}$ \\
\hline Model 2 & $\begin{array}{l}\text { T2 v.s. T1 } \\
\text { T3 v.s. T1 }\end{array}$ & $\begin{array}{l}0.95(0.71-1.28) \\
0.76(0.56-1.04)\end{array}$ & $\begin{array}{l}0.759 \\
0.082\end{array}$ & Model 2 & $\begin{array}{l}\text { T2 v.s. T1 } \\
\text { T3 v.s. T1 }\end{array}$ & $\begin{array}{l}0.67(0.39-1.14) \\
0.51(0.29-0.90)\end{array}$ & $\begin{array}{l}0.141 \\
0.021\end{array}$ \\
\hline Model 3 & $\begin{array}{l}\text { T2 v.s. T1 } \\
\text { T3 v.s. T1 }\end{array}$ & $\begin{array}{l}0.93(0.69-1.25) \\
0.73(0.53-1.00)\end{array}$ & $\begin{array}{l}0.639 \\
0.049\end{array}$ & Model 3 & $\begin{array}{l}\text { T2 v.s. T1 } \\
\text { T3 v.s. T1 }\end{array}$ & $\begin{array}{l}0.55(0.31-0.96) \\
0.40(0.22-0.73)\end{array}$ & $\begin{array}{l}0.035 \\
0.003\end{array}$ \\
\hline Model 4 & $\begin{array}{l}\text { T2 v.s. T1 } \\
\text { T3 v.s. T1 }\end{array}$ & $\begin{array}{l}0.98(0.72-1.32) \\
0.75(0.54-1.02)\end{array}$ & $\begin{array}{l}0.870 \\
0.070\end{array}$ & Model 4 & $\begin{array}{l}\text { T2 v.s. T1 } \\
\text { T3 v.s. T1 }\end{array}$ & $\begin{array}{l}0.48(0.27-0.85) \\
0.37(0.20-0.69)\end{array}$ & $\begin{array}{l}0.012 \\
0.001\end{array}$ \\
\hline \multicolumn{4}{|c|}{ Female } & \multicolumn{4}{|c|}{ Female } \\
\hline Model 1 & $\begin{array}{l}\text { T2 v.s. T1 } \\
\text { T3 v.s. T1 }\end{array}$ & $\begin{array}{l}1.45(1.20-1.75) \\
1.68(1.22-2.31)\end{array}$ & $\begin{array}{c}<0.001 \\
0.001\end{array}$ & Model 1 & $\begin{array}{l}\text { T2 v.s. T1 } \\
\text { T3 v.s. T1 }\end{array}$ & $\begin{array}{l}0.97(0.69-1.36) \\
1.55(1.01-2.38)\end{array}$ & $\begin{array}{l}0.862 \\
0.043\end{array}$ \\
\hline Model 2 & $\begin{array}{l}\text { T2 v.s. T1 } \\
\text { T3 v.s. T1 }\end{array}$ & $\begin{array}{l}1.06(0.88-1.28) \\
1.79(1.30-2.47)\end{array}$ & $\begin{array}{c}0.529 \\
<0.001\end{array}$ & Model 2 & $\begin{array}{l}\text { T2 v.s. T1 } \\
\text { T3 v.s. T1 }\end{array}$ & $\begin{array}{l}0.70(0.50-0.98) \\
1.16(0.75-1.78)\end{array}$ & $\begin{array}{l}0.040 \\
0.502\end{array}$ \\
\hline Model 3 & $\begin{array}{l}\text { T2 v.s. T1 } \\
\text { T3 v.s. T1 }\end{array}$ & $\begin{array}{l}1.06(0.88-1.28) \\
1.80(1.30-2.49)\end{array}$ & $\begin{array}{c}0.521 \\
<0.001\end{array}$ & Model 3 & $\begin{array}{l}\text { T2 v.s. T1 } \\
\text { T3 v.s. T1 }\end{array}$ & $\begin{array}{l}0.68(0.49-0.96) \\
1.08(0.70-1.67)\end{array}$ & $\begin{array}{l}0.027 \\
0.718\end{array}$ \\
\hline Model 4 & $\begin{array}{l}\text { T2 v.s. T1 } \\
\text { T3 v.s. T1 }\end{array}$ & $\begin{array}{l}1.06(0.88-1.28) \\
1.77(1.28-2.45)\end{array}$ & $\begin{array}{l}0.559 \\
0.001\end{array}$ & Model 4 & $\begin{array}{l}\text { T2 v.s. T1 } \\
\text { T3 v.s. T1 }\end{array}$ & $\begin{array}{l}0.68(0.48-0.96) \\
1.09(0.71-1.69)\end{array}$ & $\begin{array}{l}0.028 \\
0.695\end{array}$ \\
\hline
\end{tabular}

${ }^{a}$ Adjusted covariates:

Model 1 = Unadjusted.

Model 2 = Model $1+$ age, race and body mass index (BMI).

Model 3 = Model $2+$ serum high-density lipoprotein (HDL), serum fasting glucose, serum total cholesterol, serum total bilirubin, serum aspartate aminotransferase (AST).

Model $4=$ Model $3+$ history of congestive heart failure (CHF), stroke, malignancy and smoking.

LX20 instrument to measure other biochemical profiles, such as serum albumin, serum UA, serum total bilirubin, AST, and ALT. Moreover, MAMC, gamma gap, BMI, SBP, and DBP were listed as continuous variables. The database had past the appraisal of the CDC, and all the profiles were obtained under standardized protocols.

\section{Statistical analysis}

Predictive Analytics Suite Workstation Statistics (SPSS Inc., Chicago, IL, USA) (name as SPSS hereinafter) is an integrated software program that addresses the entire analytical process, from planning to data collection to analysis, reporting and deployment. NHANES III was a database with complex survey designs; thus, it was inappropriate to calculate statistical analyses with the assumption of a simple random sample providing incorrect variance estimates. "Complex Sampling" was used to incorporate sample weights and adjusted for strata of the complex sample design. Continuous data are presented as means \pm standard errors (SE) while categorical data as count and percentages (\%). To examine the effect of MAMC and gamma gap on mortality outcomes, we would describe the difference in mortality outcomes between
MAMC as a main effect. Similarly, any difference in the level of gamma gap would be presented as a main effect. The presence of an interaction effect implies that the effect of MAMC on mortality outcomes varies as a function of the level of gamma gap. As a first step, the analysis of pooled MAMC values versus pooled gamma gap levels was performed. If positive, interaction tests were performed on all-cause mortality, cancer mortality, and CV mortality to check for any interaction between the different predicting components (MAMC, gamma gap). Independent of the interaction test, an assessment of predicting effect was also performed. An interaction could be ruled out if the statistical interaction test was not significant and the assessment revealed no relevant difference. If an interaction was ruled out, the pooled analysis remained the primary analysis. If an interaction could not be ruled out, then we would divide the gamma gap into subgroups. For further analyses, the ROC curves of gamma gap for detecting all-cause mortality, cancer mortality, and CV mortality were produced. The AUCs with their 95\% CIs were calculated. To determine the optimal point, the square root of $\left[(1-\text { sensitivity })^{2}+(1-\text { specificity })^{2}\right]$ was calculated, which was the point on the ROC curve with the shortest distance from the upper left corner. The study 
would divide the participants into subgroups according to the cut-off values of gamma gap and measure the influences of MAMC stratified by age (20-39, 40-59, and 60-90 years), BMI (19-24.9, 25-29.9, and $\left.\geq 30 \mathrm{~kg} / \mathrm{m}^{2}\right)$, and gender on all-cause mortality, cancer mortality and CV mortality.

Table 1 illustrated the demographic characteristics, and the continuous variables were analyzed by trend analyses, while the categorical variables were analyzed by Chi-square test. $P$ values of less than 0.05 were considered significant.

Multivariable Cox proportional hazard ratio models stratified by age, BMI, and gender were used to explored the HRs between the MAMC tertiles ratios (T2 v.s. T1 and T3 v.s. T1) and all-cause mortality (Tables 2-4), cancer mortality (Tables 5-7), and CV mortality (Tables 8-10) in the two gamma gap groups. The multivariable Cox proportional hazard ratio models were classified into 4 models that adjusted for the following variables:

Model 1: unadjusted by other variables.

Model 2: age, gender, race and BMI.

Model 3: age, gender, race, BMI, serum HDL, serum fasting glucose, serum TC, serum total bilirubin and AST.

Model 4: age, gender, race, BMI, serum HDL, serum fasting glucose, serum TC, serum total bilirubin, AST, CHF, stroke, malignancy and smoking.

\section{Ethics statement}

The authors certify that they comply with the ethical guidelines for publishing in the Oncotarget.

\section{Authors' contributions}

Yuan-Ping Chao contributed to the design of the study, was responsible for the management and retrieval of data, contributed to initial data analysis and interpretation, and drafted the initial manuscript. Yuan-Ping Chao, YiFen Lai, Tung-Wei Kao, Tao-Chun Peng, Yuan-Yung Lin, Mu-Tsun Shih, Wei-Liang Chen, Li-Wei Wu decided upon the data collection methods. Yuan-Ping Chao and Li-Wei $\mathrm{Wu}$ were also responsible for the data analysis decisions. Li-Wei Wu conceptualized and designed the study, supervised all aspects of the study, critically reviewed and revised the manuscript, and approved the final manuscript as submitted. All authors meet the ICMJE criteria for authorship.

\section{CONFLICTS OF INTEREST}

There are no conflicts of interest.

\section{FUNDING}

The authors have received no funding for this article.

\section{REFERENCES}

1. Juraschek SP, Moliterno AR, Checkley W, Miller ER 3rd. The Gamma Gap and All-Cause Mortality. PLoS One. 2015; 10:e0143494. https://doi.org/10.1371/journal. pone. 0143494 .

2. Edwards MK, Loprinzi PD. The Association of Estimated Cardiorespiratory Fitness on mortality risk among those with an elevated gamma gap. Int J Cardiol. 2017; 227:508-510.

3. Kouassi K, Bagny A, Kaaga L, Bouglouga O, Lawson Anani-Soh L, Lamboni C, Redah D. Prevalence of protein-energy undernutrition evaluated by the measurement of triceps skinfold thickness and mid-arm muscle circumference of 103 adults with cirrhosis of the liver hospitalized in the department of hepatology and gastroenterology of the Lomé Campus University Hospital. Med Sante Trop. 2014; 24:208-213.

4. Noori N, Kopple JD, Kovesdy CP, Feroze U, Sim JJ, Murali SB, Luna A, Gomez M, Luna C, Bross R, Nissenson AR, Kalantar-Zadeh K. Mid-arm muscle circumference and quality of life and survival in maintenance hemodialysis patients. Clin J Am Soc Nephrol. 2010; 5:2258-2268.

5. Wannamethee SG, Shaper AG, Lennon L, Whincup PH. Decreased muscle mass and increased central adiposity are independently related to mortality in older men. Am J Clin Nutr. 2007; 86:1339-1346.

6. Landi F, Russo A, Liperoti R, Pahor M, Tosato M, Capoluongo E, Bernabei R, Onder G. Midarm muscle circumference, physical performance and mortality: results from the aging and longevity study in the Sirente geographic area. Clin Nutr. 2010; 29:441-447.

7. Deighan WI, O'Kane MJ, McNicholl FP, Keren DF. Multiple myeloma and multiple plasmacytomas associated with free gamma heavy chain, free kappa light chain and IgGk paraproteins: an unusual triple gammopathy. Ann Clin Biochem. 2016; 53:706-711.

8. Jou E, Gligich O, Chan AC, Mohan D, Felsen UR, Ayyappan S, Billett HH, Hui EP, Chan AT, Raghupathy R. Viral co-infections and paraproteins in HIV: effect on development of hematological malignancies. Ann Hematol. 2016; 95:575-580.

9. Preuss KD, Pfreundschuh M, Ahlgrimm M, Fadle N, Regitz E, Murawski N, Grass S. A frequent target of paraproteins in the sera of patients with multiple myeloma and MGUS. Int J Cancer. 2009; 125:656-661.

10. LeGatt DF, Blakney GB, Higgins TN, Schnabl KL, Shalapay CE, Dias VC, Wesenberg JC. The effect of paraproteins and rheumatoid factor on four commercial immunoassays for vancomycin: implications for laboratorians and other health care professionals. Ther Drug Monit. 2012; 34:306-311.

11. Ashrafi-Kooshk MR, Ebrahimi F, Ranjbar S, Ghobadi S, Moradi N, Khodarahmi R. Comparative studies on drug binding to the purified and pharmaceutical-grade human 
serum albumins: Bridging between basic research and clinical applications of albumin. Biologicals. 2015; 43:333-343.

12. Dispenzieri A, Gertz MA, Therneau TM, Kyle RA. Retrospective cohort study of 148 patients with polyclonal gammopathy. Mayo Clin Proc. 2001;76:476-487.

13. Gabay C, Kushner I. Acute-phase proteins and other systemic responses to inflammation. N Engl J Med. 1999; 340:448-454.

14. Salt HB. Serum globulin fractions in chronic rheumatic diseases; an electrophoretic study. Clin Chem. 1956; 2:35-44.

15. Kekwick RA. The serum proteins in multiple myelomatosis. Biochem J. 1940; 34:1248-1257.

16. Suh B, Park S, Shin DW, Yun JM, Keam B, Yang HK, Ahn E, Lee H, Park JH, Cho B. Low albumin-to-globulin ratio associated with cancer incidence and mortality in generally healthy adults. Ann Oncol. 2014; 25:2260-2266.

17. Loprinzi PD, Addoh O. The gamma gap and all-cause mortality risk: considerations of physical activity. Int J Clin Pract. 2016; 70:625-629.

18. Loprinzi PD, Addoh O. The effects of free-living physical activity on mortality after coronary artery disease diagnosis. Clin Cardiol. 2016; 39:165-169.

19. Warburton DE, Gledhill N, Quinney A. Musculoskeletal fitness and health. Can J Appl Physiol. 2001; 26:217-237.

20. Warburton DE, Gledhill N, Quinney A. The effects of changes in musculoskeletal fitness on health. Can J Appl Physiol. 2001; 26:161-216.

21. Berg A, Halle M, Franz I, Keul J. Physical activity and lipoprotein metabolism: epidemiological evidence and clinical trials. Eur J Med Res. 1997; 2:259-264.

22. Halle M, Berg A, von Stein T, Baumstark MW, König D, Keul J. Lipoprotein(a) in endurance athletes, power athletes, and sedentary controls. Med Sci Sports Exerc. 1996; 28:962-966.

23. American College of Sports Medicine Position Stand. Exercise and physical activity for older adults. Med Sci Sports Exerc. 1998; 30:992-1008.

24. Wallberg-Henriksson H, Rincon J, Zierath JR. Exercise in the management of non-insulin-dependent diabetes mellitus. Sports Med. 1998; 25:25-35.

25. Warburton DE, Gledhill N, Jamnik VK, Krip B, Card N. Induced hypervolemia, cardiac function, VO2max, and performance of elite cyclists. Med Sci Sports Exerc. 1999; 31:800-808.

26. Warburton DE, Haykowsky MJ, Quinney HA, Blackmore D, Teo KK, Taylor DA, McGavock J, Humen DP. Blood volume expansion and cardiorespiratory function: effects of training modality. Med Sci Sports Exerc. 2004; 36:991-1000.

27. Adamopoulos S, Piepoli M, McCance A, Bernardi L, Rocadaelli A, Ormerod O, Forfar C, Sleight P, Coats AJ. Comparison of different methods for assessing sympathovagal balance in chronic congestive heart failure secondary to coronary artery disease. Am J Cardiol. 1992; 70:1576-1582.
28. Adamopoulos S, Parissis J, Kroupis C, Georgiadis M, Karatzas D, Karavolias G, Koniavitou K, Coats AJ, Kremastinos DT. Physical training reduces peripheral markers of inflammation in patients with chronic heart failure. Eur Heart J. 2001; 22:791-797.

29. Mann DL, Young JB. Basic mechanisms in congestive heart failure: recognizing the role of proinflammatory cytokines. Chest. 1994; 105:897-904.

30. Pinsky DJ, Cai B, Yang X, Rodriguez C, Sciacca RR, Cannon PJ. The lethal effects of cytokine-induced nitric oxide on cardiac myocytes are blocked by nitric oxide synthase antagonism or transforming growth factor beta. J Clin Invest. 1995; 95:677-685.

31. Devaux B, Scholz D, Hirche A, Klövekorn WP, Schaper J. Upregulation of cell adhesion molecules and the presence of low grade inflammation in human chronic heart failure. Eur Heart J. 1997; 18:470-479.

32. Shalamzari SA, Agha-Alinejad H, Alizadeh S, Shahbazi S, Khatib ZK, Kazemi A, Saei MA, Minayi N. The effect of exercise training on the level of tissue IL- 6 and vascular endothelial growth factor in breast cancer bearing mice. Iran J Basic Med Sci. 2014; 17:231-258.

33. Hur S, Han GS, Cho BJ. Changes in Glucose, TNF- $\alpha$ and IL-6 Blood Levels in Middle-aged Women Associated with Aerobic Exercise and Meditation Training. J Phys Ther Sci. 2014; 26:1933-1936.

34. Nishida Y, Tanaka K, Hara M, Hirao N, Tanaka H, Tobina T, Ikeda M, Yamato H, Ohta M. Effects of home-based bench step exercise on inflammatory cytokines and lipid profiles in elderly Japanese females: A randomized controlled trial. Arch Gerontol Geriatr. 2015; 61:443-451.

35. Atkins JL, Whincup PH, Morris RW, Wannamethee SG. Low muscle mass in older men: the role of lifestyle, diet and cardiovascular risk factors. J Nutr Health Aging. 2014; 18:26-33.

36. Zeng P, Wu S, Han Y, Liu J, Zhang Y, Zhang E, Zhang Y, Gong $\mathrm{H}$, Pang J, Tang Z, Liu H, Zheng X, Zhang T. Differences in body composition and physical functions associated with sarcopenia in Chinese elderly: reference values and prevalence. Arch Gerontol Geriatr. 2015; 60:118-23.

37. Cruz-Jentoft AJ, Baeyens JP, Bauer JM, Boirie Y, Cederholm T, Landi F, Martin FC, Michel JP, Rolland Y, Schneider SM, Topinková E, Vandewoude M, Zamboni M. Sarcopenia: European consensus on definition and diagnosis: Report of the European Working Group on Sarcopenia in Older People. Age Ageing. 2010; 39:412-23.

38. Plan and operation of the Third National Health and Nutrition Examination Survey, 1988-94. Series 1: programs and collection procedures. Vital Health Stat 1. 1994; 1-407.

39. National Center for Health Statistics. Office of Analysis and Epidemiology, The Third National Health and Nutrition Examination Survey (NHANES III) Linked Mortality File, Mortality follow-up through 2006: Matching Methodology 
May 2009. Hyattsville, Maryland. (Available from: http://www.cdc.gov/nchs/data/datalinkage/matching methodology_nhanes3_final.pdf). (Accessed: 21 May 2014).

40. U.S. National Center for Health Statistics. 2015. NCHS Surveys. 2011 Linked Mortality Files. Public-Use Data
Dictionary. Available from: http://www.cdc.gov/nchs/data access/data_linkage/mortality.htm. 